\title{
Impaired pulmonary vasomotor control in exercising swine with multiple comorbidities
}

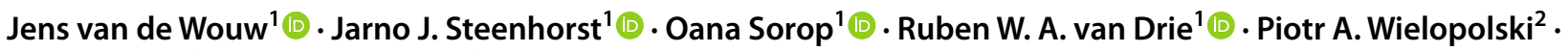 \\ Alex Kleinjan $^{3}$ - Alexander Hirsch ${ }^{2,4}$. Dirk J. Duncker ${ }^{1}$ (D) Daphne Merkus ${ }^{1,5,6}$
}

Received: 2 June 2020 / Accepted: 29 July 2021 / Published online: 12 September 2021

(C) The Author(s) 2021

\begin{abstract}
Pulmonary hypertension is common in heart failure with preserved ejection fraction (HFpEF). Here, we tested the hypothesis that comorbidities [diabetes mellitus (DM, streptozotocin), hypercholesterolemia (HC, high-fat diet) and chronic kidney disease (CKD, renal microembolization)] directly impair pulmonary vasomotor control in a $\mathrm{DM}+\mathrm{HC}+\mathrm{CKD}$ swine model. 6 months after induction of $\mathrm{DM}+\mathrm{HC}+\mathrm{CKD}$, pulmonary arterial pressure was similar in chronically instrumented female DM $+\mathrm{HC}+\mathrm{CKD}(n=19)$ and Healthy swine $(n=18)$. However, cardiac output was lower both at rest and during exercise, implying an elevated pulmonary vascular resistance (PVR) in DM $+\mathrm{HC}+\mathrm{CKD}$ swine $\left(153 \pm 10\right.$ vs. $\left.122 \pm 9 \mathrm{mmHg} \bullet \mathrm{L}^{-1} \bullet \mathrm{min} \bullet \mathrm{kg}\right)$. Phosphodiesterase 5 inhibition and endothelin receptor antagonism decreased PVR in DM + HC + CKD $\left(-12 \pm 12\right.$ and $\left.-22 \pm 7 \mathrm{mmHg} \bullet \mathrm{L}^{-1} \bullet \mathrm{min} \bullet \mathrm{kg}\right)$ but not in Healthy swine $(-1 \pm 12$ and $2 \pm 14 \mathrm{mmHg} \bullet \mathrm{L}^{-1} \bullet \mathrm{min} \bullet \mathrm{kg}$ ), indicating increased vasoconstrictor influences of phosphodiesterase 5 and endothelin. Inhibition of nitric oxide synthase produced pulmonary vasoconstriction that was similar in Healthy and DM $+\mathrm{HC}+\mathrm{CKD}$ swine, but unmasked a pulmonary vasodilator effect of endothelin receptor antagonism in Healthy $\left(-56 \pm 26 \mathrm{mmHg} \bullet \mathrm{L}^{-1} \bullet \mathrm{min} \bullet \mathrm{kg}\right)$, whereas it failed to significantly decrease PVR in DM + HC + CKD, indicating loss of nitric oxide mediated inhibition of endothelin in DM + HC + CKD. Scavenging of reactive oxygen species (ROS) had no effect on PVR in either Healthy or $\mathrm{DM}+\mathrm{HC}+\mathrm{CKD}$ swine. Cardiovascular magnetic resonance imaging, under anesthesia, showed no right ventricular changes. Finally, despite an increased contribution of endogenous nitric oxide to vasomotor tone regulation in the systemic vasculature, systemic vascular resistance at rest was higher in $\mathrm{DM}+\mathrm{HC}+\mathrm{CKD}$ compared to Healthy swine ( $824 \pm 41$ vs. $698 \pm 35 \mathrm{mmHg} \bullet \mathrm{L}^{-1} \bullet \mathrm{min} \bullet \mathrm{kg}$ ). ROS scavenging induced systemic vasodilation in DM+HC + CKD, but not Healthy swine. In conclusion, common comorbidities directly alter pulmonary vascular control, by enhanced PDE5 and endothelin-mediated vasoconstrictor influences, well before overt left ventricular backward failure or pulmonary hypertension develop.
\end{abstract}

Keywords Diabetes mellitus $\cdot$ Chronic kidney disease $\cdot$ Pulmonary hypertension $\cdot$ Endothelin $\cdot$ Nitric oxide

Jens van de Wouw and Jarno J. Steenhorst have contributed equally.

Daphne Merkus

d.merkus@erasmusmc.nl

1 Division of Experimental Cardiology, Department of Cardiology, Erasmus MC, University Medical Center Rotterdam, PO Box 2040, 3000 CA Rotterdam, The Netherlands

2 Department of Radiology and Nuclear Medicine, Erasmus MC, University Medical Center Rotterdam, Rotterdam, The Netherlands

3 Department of Pulmonary Medicine, Erasmus MC, University Medical Center Rotterdam, Rotterdam, The Netherlands
4 Department of Cardiology, Erasmus MC, University Medical Center Rotterdam, Rotterdam, The Netherlands

5 Institute for Surgical Research, Walter Brendel Center of Experimental Medicine (WBex), University Clinic Munich, LMU Munich, Munich, Germany

6 German Center for Cardiovascular Research, Partner Site Munich, Munich Heart Alliance, Munich, Germany 


\section{Introduction}

Pulmonary vascular disease (PVD) is prevalent in a large proportion of patients with heart failure with preserved ejection fraction (HFpEF); about one out of four patients meet the criteria of overt pulmonary hypertension $(\mathrm{PH})$ in this population (mean pulmonary arterial (PA) pressure $>25 \mathrm{mmHg}$ at rest), which is associated with increased mortality and cardiac hospitalization [31, $32,60]$. It is increasingly recognized that even a slightly elevated PA pressure - above $19 \mathrm{mmHg}$ - is a strong predictor of increased hospitalizations and higher mortality $[11,35]$, underlining the importance of early recognition and treatment of PVD. Although the early symptoms of PVD can be subtle at rest, exercise is able to reveal PVD in an early stage in patients with cardiopulmonary diseases, including HFpEF [18, 21, 31, 34].

Common comorbidities for cardiovascular disease, including diabetes mellitus (DM), hypercholesterolemia (HC), chronic kidney disease (CKD), are independentlybut especially in combination-well-known risk factors for the development of HFpEF [10, 43]. The current paradigm of HFpEF implies a crucial role for coronary microvascular dysfunction, due to a systemic pro-inflammatory state, in its development [19, 43]. Yet, the pro-inflammatory state is not restricted to the coronary microvasculature and hence, other vascular beds-not only the systemic, but also the pulmonary vasculature-may also be directly affected [48]. Indeed, PH is highly prevalent in patients with CKD $[6,51]$. Thus, contrary to the current belief that $\mathrm{PH}$ progresses from early post-capillary $\mathrm{PH}$ due to elevated left atrial pressures, to combined pre- and postcapillary $\mathrm{PH}$ with pulmonary vascular changes, a direct detrimental effect of the systemic pro-inflammatory state on the pulmonary vasculature may also be present, suggesting that PVD could develop prior to overt HFpEF-PH in a subgroup of patients. This pro-inflammatory state may induce pulmonary endothelial dysfunction reflected by an imbalance between the influences of the vasoconstrictor endothelin (ET) and the vasodilator nitric oxide (NO) on control of pulmonary vascular tone [41].

In light of these considerations, we aimed to investigate the effects of a chronic pro-inflammatory state, induced by 5 months of DM, HC and CKD, on pulmonary microvascular and right ventricular (RV) structure and function. The effects of DM, HC and CKD on the systemic and pulmonary vascular function were assessed with a focus on endothelial dysfunction, and the balance between NO and ET, in chronically instrumented female swine with $\mathrm{DM}+\mathrm{HC}+\mathrm{CKD}$ at rest and during graded treadmill exercise $[50,55]$.

\section{Materials and methods}

\section{Animals}

All animal experiments were approved by the Animal Care Committee at the Erasmus University Medical Center (Rotterdam, The Netherlands) and in accordance with the "Guiding Principles in the Care and Use of Laboratory Animals" as approved by the National Research Council of the National Academies. 19 female Yorkshire $\times$ landrace swine $(24 \pm 1 \mathrm{~kg})$ were included in the experimental group $(\mathrm{DM}+\mathrm{HC}+\mathrm{CKD})$ while 18 healthy female Yorkshire $\times$ landrace swine of similar age and weight were used as controls (Healthy).

\section{Induction of risk factors}

The induction of risk factors in the $\mathrm{DM}+\mathrm{HC}+\mathrm{CKD}$ group has been described in detail elsewhere [50]. Briefly, DM was produced by injection of streptozotocin (AdipoGen Life Sciences, San Diego, CA, USA) in a dose of $50 \mathrm{mg} \bullet \mathrm{kg}^{-1}$ per day i.v. on three consecutive days. The severity and stability of DM was monitored bi-weekly by measurements of blood glucose and ketone levels.

2 weeks after DM induction, animals were sedated with intramuscular injection of a cocktail of Zoletil (tiletamine/ zolazepam; $5 \mathrm{mg} \cdot \mathrm{kg}^{-1}$ ), Sedazine (xylazine; $2.25 \mathrm{mg} \cdot \mathrm{kg}^{-1}$ ) and atropine $(2 \mathrm{mg})$ and artificially ventilated $\left(\mathrm{O}_{2}\right.$ and $\mathrm{N}_{2}$ [1:2 vol/ $\mathrm{vol}]$, to which $1-2 \%$ ( $\mathrm{vol} / \mathrm{vol})$ isoflurane was added for anesthesia). CKD was produced by microembolization of the global right kidney as well as the lower pole of the left kidney. For this purpose, the renal arteries were catheterized under fluoroscopy guidance (right renal artery and selective catheterization of the artery perfusing the left lower renal pole) with a Swan-Ganz catheter, inserted through a $9 \mathrm{~F}$ sheath in the right common carotid artery. Following inflation of the balloon to prevent back-flow into the aorta, $75 \mathrm{mg}$ of polyethylene microspheres with a diameter of 38-42 $\mu \mathrm{m}$ (Cospheric, Santa Barbara, CA, USA) were infused in each kidney. The wound was closed and the animals were allowed to recover.

1 week after CKD induction, a high-fat and high-sugar diet containing $10 \%$ sucrose, $15 \%$ fructose, $25 \%$ saturated fats and $1 \%$ cholesterol (Research Diets Services BV, Wijk bij Duurstede, The Netherlands) supplemented with sodium chloride ( $20 \mathrm{~g}$ per day) was gradually introduced. The Healthy group continued to receive regular swinechow. Animals were housed in pairs but were fed separately and had ad libitum access to drinking water.

The animals were divided into two groups; one group (12 DM + HC + CKD and 12 Healthy) was chronically 
instrumented 5 months following induction of the risk factors, as described elsewhere [9], and renal function measurements and exercise experiments were performed 1-3 weeks later. The second group (7 DM + HC + CKD and 6 Healthy) underwent cardiovascular magnetic resonance imaging (CMR) using a 1.5-T scanner 6 months after induction of the risk factors and sacrificed afterwards.

\section{Instrumentation}

As mentioned above, one group of animals underwent chronic instrumentation after 5 months and was terminated 1 month later. For chronic instrumentation, swine were sedated, intubated and anesthetized as described above. As described elsewhere [9], a thoracotomy was performed in the fourth left intercostal space under sterile conditions. After opening of the pericardium, fluid-filled polyvinylchloride catheters (Braun Medical Inc., Bethlehem, PA, USA) were inserted into the pulmonary artery $(2 \times)$, the aortic arch, the left atrium $(2 \times)$ and the right ventricle to allow hemodynamic measurements and extraction of blood samples. A transit-time flow probe (Transonic Systems Inc., Ithaca, NY, USA) was placed around the ascending aorta for measurement of cardiac output (CO) [9]. Electrical wires and catheters were tunneled subcutaneously to exit at the back and protected with a vest. Then, the chest was closed in layers, and animals were allowed to recover, receiving analgesia $(0.3 \mathrm{mg}$ buprenorphine i.m. once) and a slow-release fentanyl patch $\left(50 \mu \mathrm{g} \mathrm{h}^{-1}\right)$ and antibiotic prophylaxis $\left(25 \mathrm{mg} \bullet \mathrm{kg}^{-1}\right.$ amoxicillin i.v.) for 7 days. All catheters were flushed daily with heparinized saline (1000-5000 $\mathrm{IU} \mathrm{ml}^{-1}$ saline) to prevent the formation of blood clots and to ensure catheter patency [9].

\section{Exercise experiments}

After 1 week of recovery, exercise experiments were conducted on a motor-driven treadmill. Briefly, resting hemodynamic measurements, blood samples and rectal temperature were obtained with swine standing quietly on the treadmill. Subsequently, all swine were subjected to a three-stage incremental treadmill exercise protocol $\left(2-4 \mathrm{~km} \cdot \mathrm{h}^{-1}\right.$ at $0 \%$ inclination, 3 min per speed). Hemodynamic variables, consisting of heart rate, cardiac output, aortic pressure, PA pressure, left atrial pressure and RV pressure were continuously recorded digitally on a Codas workstation (ATCODAS, Dataq Instruments, Akron, OH, USA) with blood samples collected at rest and during the final $30 \mathrm{~s}$ of each 3-min exercise stage when steady-state hemodynamics had been achieved. Blood samples were analyzed for $\mathrm{PO}_{2}, \mathrm{PCO}_{2}, \mathrm{pH}$, $\mathrm{O}_{2}$ saturation and hemoglobin concentration (ABL-800, Radiometer, Copenhagen, Denmark).

After $60 \mathrm{~min}$ of rest or on a following day the same exercise protocol was conducted while nitric oxide synthase (NOS), phosphodiesterase 5 (PDE5), endothelin receptor $\mathrm{A}$ and $\mathrm{B}\left(\mathrm{ET}_{\mathrm{A}} / \mathrm{ET}_{\mathrm{B}}\right)$, or reactive oxygen species (ROS) were inhibited. An overview of the number of animals in the different protocols, and the number of overlapping animals between protocols is given in Table 1. NOS inhibition (NOSi) was achieved by $20 \mathrm{mg} \cdot \mathrm{kg}^{-1}$ i.v. infusion of N $\omega$-nitro-L-arginine (L-NNA, Sigma-Aldrich, Saint Louis, MO, USA), 15 min after L-NNA infusion, samples were obtained at rest and the exercise protocol was started. PDE5 inhibition (PDE5i) was achieved by administration of $10 \mathrm{mg}$ Sildenafil (Revatio, Pfizer Inc, New York, NY, USA); 5 min after complete infusion resting samples were obtained and the exercise protocol was started. Endothelin receptor inhibition $\left(\mathrm{ET}_{\mathrm{A}+\mathrm{B}} \mathrm{i}\right)$ was achieved by infusion of the mixed $\mathrm{ET}_{\mathrm{A}} / \mathrm{ET}_{\mathrm{B}}$ receptor blocker Tezosentan (a gift from Actelion
Table 1 Schematic overview of swine used in various exercise protocols, as well as overlap between groups

\begin{tabular}{lllllll}
\hline Experiment & Con & $\mathrm{ET}_{\mathrm{A}+\mathrm{B}} \mathrm{i}$ & NOSi & NOSi/ET $_{\mathrm{A}+\mathrm{B}} \mathrm{i}$ & PDE5i & ROSi \\
\hline Con & $\begin{array}{l}\text { Diseased 12 } \\
\text { Healthy 11 }\end{array}$ & Healthy 6 & Healthy 7 & Healthy 5 & Healthy 6 & Healthy 8 \\
& Diseased 6 & $\begin{array}{l}\text { Diseased 6 } \\
\text { Healthy 6 }\end{array}$ & Healthy 4 & Healthy 5 & Healthy 6 & Healthy 5 \\
NOSi & Diseased 6 & Diseased 4 & $\begin{array}{l}\text { Diseased 6 } \\
\text { Healthy 7 }\end{array}$ & Healthy 5 & Healthy 5 & Healthy 4 \\
NOSi/ET ${ }_{\mathrm{A}+\mathrm{B}} \mathrm{i}$ & Diseased 4 & Diseased 4 & Diseased 3 & $\begin{array}{l}\text { Diseased 4 } \\
\text { Healthy 6 }\end{array}$ & Healthy 6 & Healthy 6 \\
PDE5i & Diseased 7 & Diseased 4 & Diseased 3 & Diseased 3 & $\begin{array}{l}\text { Diseased 7 } \\
\text { Healthy 7 }\end{array}$ & Healthy 6 \\
ROSi & Diseased 8 & Diseased 5 & Diseased 6 & Diseased 3 & Diseased 4 & Diseased 8 \\
& & & & & Healthy 8 \\
\hline
\end{tabular}

Numbers in bold denote the total numbers in a protocol, diseased reflect animal with $\mathrm{DM}+\mathrm{HC}+\mathrm{CKD}$ Con control exercise experiment without pharmacological intervention, NOSi nitric oxide inhibition, $E T_{A+B} i$ endothelin receptor $\mathrm{A}$ and $\mathrm{B}$ antagonism, PDE5i phosphodiesterase 5 inhibition, ROS $i$ scavenging of reactive oxygen species 
Pharmaceuticals Ltd, Allschwil, Switzerland, dosage: bolus of $300 \mu \mathrm{g} \bullet \mathrm{kg}^{-1} \bullet \mathrm{min}^{-1}$ over $10 \mathrm{~min}$ i.v. followed by continuous infusion of $100 \mu \mathrm{g} \cdot \mathrm{kg}^{-1} \bullet \mathrm{min}^{-1}$ i.v.) during the exer-

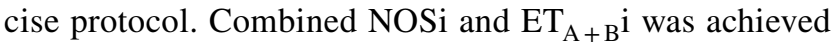
by inhibition of NOS as described above, followed $15 \mathrm{~min}$ later, by $\mathrm{ET}_{\mathrm{A}+\mathrm{B}} \mathrm{i}$ using the same protocol as described above. ROS scavenging was achieved by continuous infusion of $1 \mathrm{mg} \cdot \mathrm{kg}^{-1} \cdot \mathrm{min}^{-1}$ of free radical scavenger $\mathrm{N}$-(2-mercaptopropionyl)glycine (MPG, Sigma-Aldrich, Zwijndrecht, The Netherlands) and $30 \mathrm{mg} \cdot \mathrm{kg}^{-1}$ i.v. infusion of superoxide dismutase mimetic 4-hydroxy-2,2,6,6-tetramethylpiperidine$N$-oxyl (Tempol, Sigma-Aldrich, Zwijndrecht, The Netherlands). After 10 min of infusion, samples were obtained at rest and exercise protocol was started.

\section{Cardiovascular magnetic resonance imaging acquisition and analysis}

The second group of animals (DM $+\mathrm{HC}+\mathrm{CKD} n=7$ and Healthy $n=6$ ) underwent CMR 6 months after induction of the comorbidities. The animals were sedated with an intramuscular injection of Zoletil (tiletamine/zolazepam; $5 \mathrm{mg} \cdot \mathrm{kg}^{-1}$ ), Sedazine (xylazine; $2.25 \mathrm{mg} \bullet \mathrm{kg}^{-1}$ ) and atropine $\left(2 \mathrm{mg}\right.$ ), anesthetized with pentobarbital (bolus of $20 \mathrm{mg} \bullet \mathrm{kg}^{-1}$ followed by $10 \mathrm{mg} \cdot \mathrm{kg}^{-1} \cdot \mathrm{h}^{-1}$ i.v. during CMR) and sacrificed afterwards. Swine were placed in lateral position and mechanical ventilation and breath-holds were performed using a mobile ventilator (Carina, Dräger Medical, Best, The Netherlands). CMR was performed on a 1.5-T clinical scanner with a dedicated 32-channel phased-array surface coil (Discovery MR450, GE Healthcare, Milwaukee, Wisconsin, USA). The imaging protocol consisted of retrospectively ECG-gated 2D balanced Steady-State Free Precession cine imaging with breath-holding (FIESTA, GE Healthcare acronym). Standard long-axis and short-axis images with full left ventricle and RV coverage were obtained. Typical scan parameters were slice thickness $6.0 \mathrm{~mm}$, slice gap $0 \mathrm{~mm}$, TR/TE 3.3/1.4 ms, flip angle $60^{\circ}$, NEX 2, field of view $288 \times 360 \mathrm{~mm}$, acquired matrix $160 \times 192$, and number of reconstructed phases 24 per cardiac cycle. To assess $\mathrm{RV}$ volumes, endocardial contours were drawn manually on end-diastolic and end-systolic short axis cine images. Volumes were measured and ejection fraction was calculated. All volumes were indexed for body weight. RV global longitudinal strain (GLS) was measured using the 4-chamber longitudinal axis by manually drawing endocardial contours during end-diastole and end-systole of the RV with subsequent automatic tracking during the entire cardiac cycle. The analyses were done with QMass (version 8.1) and QStrain (version 2.0) analytical software from Medis Medical Imaging Systems BV (Leiden, The Netherlands).

\section{Termination}

At sacrifice the animals were sedated with intravenous infusion of Zoletil (tiletamine/zolazepam; $5 \mathrm{mg} \cdot \mathrm{kg}^{-1}$ ), Sedazine (xylazine; $2.25 \mathrm{mg} \cdot \mathrm{kg}^{-1}$ ) and atropine $(2 \mathrm{mg}$ ) and anesthetized with pentobarbital (bolus of $20 \mathrm{mg} \cdot \mathrm{kg}^{-1}$ followed by $10 \mathrm{mg} \cdot \mathrm{kg}^{-1} \cdot \mathrm{h}^{-1}$ i.v.). Subsequently, a sternotomy was performed and ventricular fibrillation was induced using a $9 \mathrm{~V}$ battery, and immediately the heart and lungs were excised and stored for later analysis.

\section{Plasma measurements}

Fasting arterial blood samples were obtained at instrumentation (5 months follow-up) or immediately after CMR (6 months follow-up) for determination of plasma glucose, triglycerides, total cholesterol, low-density lipoprotein (LDL), high-density lipoprotein (HDL) and creatinine. Arterial plasma concentrations of tumor necrosis factor alpha (TNF- $\alpha$, R\&D Systems Inc., Minneapolis, MN, USA) and endothelin-1 (ET-1, Enzo Life Sciences International Inc., Farmingdale, NY, USA) were determined using ELISA kits, according to the manufacturer's protocol. NO metabolites, nitrite and nitrate $\left(\mathrm{NO}_{2}{ }^{-}+\mathrm{NO}_{3}{ }^{-}\right)$, were determined using a colorimetric Griess reaction assay (BioVision Inc., Milpitas, CA, USA). The glomerular filtration rate (GFR) was measured in chronically instrumented animals using continuous inulin infusion $\left(19 \mathrm{mg} \bullet \mathrm{min}^{-1}\right.$, Inutest Fresenius Pharma, Austria, GmbH) and plasma sampling at rest. Three consecutive 20 min inulin clearance periods were averaged.

\section{Histological measurements}

Samples of the lung and RV wall were excised, fixated in $4 \%$ buffered formaldehyde and embedded in paraffin for histological analyses. RV wall sections ( $4.5 \mu \mathrm{m}$ thick) were stained for quantification of myocardial collagen deposition, myocyte size and capillary density. Six to eight fields were examined in the subendocardial half of each slide, at $20 \times$ magnification. Interstitial collagen deposition was assessed using picrosirius red staining, with perivascular collagen deposition being excluded from the analysis. A polarization filter differentiated between collagen type I and III fibers [59]. The areas occupied by the different types of collagen fibers were measured and expressed as a percentage of the myocardial area. Cross-sectional areas of cardiomyocytes with clearly visible nuclei were measured for each slide, using a Gomori silver stain. Capillary density per $\mathrm{mm}^{2}$ myocardial area was quantified using an endothelial cell staining with biotin-labeled lectin (lectin 1/100 in $1 \%$ bovine serum albumin in PBS, Sigma-Aldrich, Zwijndrecht, The Netherlands). All vessels smaller than $10 \mu \mathrm{m}$ in diameter and without vascular smooth muscle cells were 
counted. Capillary density was divided by the number of cardiomyocytes per $\mathrm{mm}^{2}$, quantified in Gomori stained sections, to calculate capillary-to-fiber ratios. All measurements were performed using a microscopy image analysis system (Impak C, Clemex Vision Image analysis system, Clemex Technologies, Quebec, Canada) and by a blinded observer.

After excision of the lungs, the accessory lobe was inflated and perfusion-fixated with $4 \%$ buffered formaldehyde at a pressure of $25 \mathrm{~cm} \mathrm{H}_{2} \mathrm{O}$ and embedded in paraffin. Vascular structure was assessed in pressure fixated lung tissue using a Resorcin-Fuchsin-Van Gieson's (RF) staining was performed to discriminate the internal and external elastic lamina of small pulmonary arteries. Using the Hamamatsu NanoZoomer Digital Pathology (NDP) slide scanner (Hamamatsu Nanozoomer 2.0HT, Hamamatsu Photonics K.K., Hamamatsu City, Japan), whole section images were obtained. Morphometric measurements of pulmonary small arteries were performed using NDP viewer (Hamamatsu) by a blinded observer. Both internal and external elastic lamina areas were measured and assuming circularity of the vessels, inner and outer radius were calculated as $r=\sqrt{ }($ area/ $\pi)$. Wall-to-lumen ratio was calculated as (outer - inner radius)/ inner radius, and relative lumen area as inner/outer area. To ensure that pulmonary veins were excluded from analysis, vessels in close proximity to the intersegmental septae were excluded from analysis. Only transversely cut vessels with an outer diameter of 30-120 $\mu \mathrm{m}$ were analyzed.

Endothelial cells were labelled with lectin (1:100 in 1\% bovine serum albumin in TBS, Sigma-Aldrich, Saint Louis, MO, USA) and smooth muscle cells with a monoclonal mouse anti-human smooth muscle actin (SMA, 1:500 diluted with $1 \%$ bovine serum albumin in TBS, Agilent Technologies, Santa Clara, CA, USA) using a double stain system (DAKO EnVision G, Agilent Technologies). Following image digitization using the Hamamatsu NanoZoomer Digital Pathology (NDP) slide scanner, whole section images were obtained. Morphometric measurements of pulmonary small arteries were performed using NDP viewer (Hamamatsu) in ten random selected digital sections of $2 \times 1 \mathrm{~mm}$ per animal. Vessels $(10-30 \mu \mathrm{m})$ were selected and divided in four quadrants, and a quadrant was scored positive for the presence of SMA if more than half of the quadrant was covered [total vessel score ranging from 0 (no SMA) to 4 (completely surrounded by SMA)] by a blinded observer and checked by a second blinded observer.

Endothelin $\mathrm{B}\left(\mathrm{ET}_{\mathrm{B}}\right)$ receptor staining of the vascular endothelium was performed on $4 \mu \mathrm{m}$ thick cryo-preserved lung tissue sections, (1:1000 rabbit anti-ET ${ }_{B}$, ab117529, Abcam, Cambridge, UK). Arterioles ranging between 20 and $60 \mu \mathrm{m}$ in diameter were selected and the lumen divided in four quadrants. Scores were given ranging from 0 (no $\mathrm{ET}_{\mathrm{B}}$ receptor staining in the endothelium) to 4 (endothelium completely stained for $\mathrm{ET}_{\mathrm{B}}$ receptor), by a blinded observer and checked by a second blinded observer. If more than half of the quadrant showed endothelial positive staining for the $\mathrm{ET}_{\mathrm{B}}$ receptor, the quadrant was scored positive.

Pulmonary vascular airway inflammation was assessed using a hematoxylin-eosin (HE) staining on pressure fixated lung tissue in a semi-quantitative way by an experienced, blinded observer. If infiltrates were centered around pulmonary arteries and veins, the inflammation of the areas were scored from 0 to 4, 0 -no inflammation; 1 -partial diffuse inflammation; 2-generalized diffuse infiltration; 3 - diffuse and focal dense infiltration and 4-strong focal dense infiltration. An area of at least $0.5 \mathrm{~cm}^{2}$ was evaluated in each slide including bronchial tissue and pulmonary arteries and veins and parenchyma.

\section{Molecular analyses}

Gene expression of several anti-oxidant enzymes, the endothelin system, endothelial and inducible NO synthase, and PDE5 was measured in snapfrozen lung tissue. Total RNA was isolated from bulk lung tissue samples. RNA purity and concentration were measured and cDNA synthesis (SensiFAST cDNA synthesis kit, Bioline, London, UK) was performed using $500 \mathrm{ng}$ RNA as input. Gene expression was analyzed on the CFX96 Real-Time PCR detection system (Biorad, Hercules, CA, USA) using the SensiMix SYBR-green supermix (Bioline). The genes investigated and the primers used are shown in Table 2. Results were normalized to the housekeeping genes RPL13A and Cyclophilin $\mathrm{A}$ and relative changes in expression levels were calculated using the BioRad CFX software.

Total endothelial NOS (eNOS), phosphorylated eNOS (Ser1177 site), vasodilator-stimulated phosphoprotein (VASP), phosphorylated VASP, eNOS monomer and dimer protein levels were determined in frozen, homogenized bulk pulmonary tissue samples. For detection of eNOS monomer and dimer fractions, low temperature SDS-PAGE in the absence of $\beta$-mercaptoethanol was performed as previously described [50]. Briefly, gels and buffers were equilibrated at $4{ }^{\circ} \mathrm{C}$ before electrophoresis, and the buffer tank was placed in an ice bath during electrophoresis to maintain the low temperature. SDS-PAGE for phosphorylated eNOS, total eNOS protein content and housekeeping protein GAPDH was performed at room temperature. Following SDS-PAGE, the proteins were transferred to nitrocellulose membranes and the blots were probed with primary anti-phospho eNOS Ser1177 (1:1000, purified monoclonal rabbit anti-human eNOS, CST9570, Cell Signalling Technology Inc., Danvers, MA, USA), anti-eNOS (1:500, purified monoclonal Mouse anti-human eNOS, 610297, Transduction Laboratory, BD Biosciences, San Jose, CA, USA), anti-VASP (1:1000, purified monoclonal rabbit anti-human VASP, CST3132, Cell Signalling Technology Inc.) anti-phospho 
Table 2 Genes and primer sequences used for qPCR

\begin{tabular}{lll}
\hline Gene & Forward sequence & Backward sequence \\
\hline CAT & TGCCACCGGCAACTATCCCT & TCGCTGTGAGGCCAAACCTTG \\
CYPA & AGACAGCAGAAAACTTCCGTG & AAGATGCCAGGACCCGTATG \\
ECE-1 & CTGCAGGCACCGTTCTACACC & CCACGACGACGCCGATGCCAC \\
EDNRA & TCTGCGCTCTCAGTGTTGAC & AGCCGATTGCTTCAGGGATG \\
EDNRB & GGAAATCGCCTGCGAATCTG & TGGCTAGTGGCAAGCAGAAA \\
GPX1 & ACCGACCCCAAGTTTATCAC & CATCAGGTGTTCCTCCACA \\
NOS2 & TCCAGGCAATGGAGAGAAAC & CCGAACACAGCATACCTGAA \\
NOS3 & GGACACACGGCTAGAAGAGC & TCCGTTTGGGGCTGAAGATG \\
PDE5 & GCCACTCAATCATGGAGCATC & GGAGAGGCCACTGAGAATCTG \\
PPET & TTCATCGGCAGCTGGTGATGG & CTTATCTCTGTAGAGCTCGGC \\
RPL13A & TGGCCAAGCAGGTACTTCTG & GTATTCATGCGCTTGCGGAG \\
SOD1 & CATTCCATCATTGGCCGCAC & CCCAATTACACCACAGGCCA \\
SOD2 & GGCCTACGTGAACAACCTGA & TGATTGATGTGGCCTCCACC \\
SOD3 & CAGACACACTCTCCGCTTCT & AGACCTTCGGGGTAAATGG \\
\hline
\end{tabular}

$C A T$ catalase, CYPA cyclophilin A, ECE-1 endothelin converting enzyme, EDNRA endothelin receptor A, $E D N R B$ endothelin receptor B, GPX1 glutathione peroxidase, NOS2 inducible nitric oxide synthase, NOS3 endothelial nitric oxide synthase, PDE5 phosphodiesterase 5, PPET prepro-endothelin 1, RPL13A ribosomal protein L13a, SOD superoxide dismutase
VASP Ser239 (1:1000, purified polyclonal rabbit anti-human VASP, CST3114, Cell Signalling Technology Inc.) and anti-GAPDH (1:1000, 14C10, Cell Signalling Technology Inc.). All blots were analyzed using the Odyssey CLX imaging system (LI-COR Biotechnology, Lincoln, NE, USA).

\section{Data analysis and statistics}

Off-line analysis of hemodynamics was performed using CODAS and Matlab. Hemodynamic data were averaged over $10 \mathrm{~s}$. Body $\mathrm{O}_{2}$ consumption indexed for body weight $\left(\mathrm{BVO}_{2}\right)$ was computed by (cardiac output/body weight) $\times$ (arterial $\mathrm{O}_{2}$ content - mixed venous $\mathrm{O}_{2}$ content). SVR was calculated as mean arterial pressure/(cardiac output/body weight). Transpulmonary gradient (TPG) was computed by mean pulmonary arterial pressure - mean left atrial pressure. Pulmonary vascular resistance indexed for body weight (PVR) was computed by (mean pulmonary arterial pressure - left atrial pressure)/(cardiac output/body weight). Ea was computed by mean pulmonary arterial pressure/(stroke volume/body weight). Compliance was computed by (stroke volume/body weight)/(systolic - diastolic pulmonary pressure). Data were tested for normality using the Shapiro-Wilk and Kolmogorov-Smirnov test. Data showing a normal distribution are presented as mean \pm SEM, whereas data without normal distribution are shown as median [interquartile range (IQR)]. Statistical analysis of hemodynamic data was performed in SPSS Statistics 21.0 (IBM Corp, Armonk, NY, USA), using a two-way ANCOVA for treatment effects and between group differences, with $\mathrm{BVO}_{2}$ as covariate. Comparison of other variables between the two groups was performed by unpaired Student's $t$ test for parametric data or Mann-Whitney $U$ test for non-parametric data. Statistical significance was accepted when $P \leq 0.05$ (two-tailed), and $P \leq 0.10$ (two-tailed) was accepted as a statistical trend.

\section{Results}

\section{Model characteristics}

As shown in Table 3, metabolic dysfunction in $\mathrm{DM}+\mathrm{HC}+\mathrm{CKD}$ swine was evidenced by markedly elevated levels of plasma glucose, total cholesterol, LDL/HDL ratio and triglycerides as compared to Healthy swine. Renal dysfunction was present in $\mathrm{DM}+\mathrm{HC}+\mathrm{CKD}$ swine reflected by increased creatinine plasma levels and a significantly lower glomerular filtration rate (GFR). Metabolic and renal dysfunction resulted in a systemic pro-inflammatory state as indicated by a higher TNF- $\alpha$ and ET-1 plasma levels.

\section{Pulmonary and systemic hemodynamics}

Although the exercise-induced increase in heart rate was blunted in $\mathrm{DM}+\mathrm{HC}+\mathrm{CKD}$ swine, the relation between heart rate and body oxygen consumption $\left(\mathrm{BVO}_{2}\right)$ was unaltered compared to Healthy swine (Fig. 1). Mean arterial pressure (at rest: $88 \pm 3 \mathrm{mmHg}$ in Healthy vs $87 \pm 2 \mathrm{mmHg}$ in $\mathrm{DM}+\mathrm{HC}+\mathrm{CKD}$ ) and left atrial pressure were also similar, but cardiac index was lower for any given level of $\mathrm{BVO}_{2}$, indicating an increased systemic vascular resistance (SVR) (Fig. 1). Respiratory function was maintained as arterial oxygenation was similar between groups both at rest and during exercise, (Fig. 1). Furthermore, although 
Table 3 Metabolic, renal, inflammatory parameters and pulmonary anti-oxidant systems of Healthy and $\mathrm{DM}+\mathrm{HC}+\mathrm{CKD}$ swine

\begin{tabular}{|c|c|c|}
\hline & Healthy $(n=18)$ & $\mathrm{DM}+\mathrm{HC}+\mathrm{CKD}(n=19)$ \\
\hline Body weight (kg) & $98 \pm 3$ & $94 \pm 4$ \\
\hline \multicolumn{3}{|l|}{ Metabolic function } \\
\hline Plasma fasting glucose $\left(\mathrm{mmol} \mathrm{L}^{-1}\right)$ & $7.2 \pm 0.6$ & $21.3 \pm 1.1^{*}$ \\
\hline Plasma total cholesterol $\left(\mathrm{mmol} \mathrm{L}^{-1}\right)$ & $1.80(1.60-2.25)$ & $11.80(7.30-21.20)^{*}$ \\
\hline LDL/HDL cholesterol ratio & $1.22(1.04-1.37)$ & $2.97(1.81-4.43)^{*}$ \\
\hline Plasma triglycerides $\left(\mathrm{mmol} \mathrm{L}^{-1}\right)$ & $0.23(0.16-0.28)$ & $0.47(0.27-0.82)^{*}$ \\
\hline \multicolumn{3}{|l|}{ Renal function } \\
\hline Plasma creatinine $\left(\mu \mathrm{mol} \mathrm{L}{ }^{-1}\right)$ & $126(107-135)$ & $157(136-179)^{*}$ \\
\hline $\operatorname{GFR}\left(\mathrm{ml} \mathrm{min}^{-1}\right)^{\mathrm{a}}$ & $196 \pm 11$ & $129 \pm 12 *$ \\
\hline \multicolumn{3}{|l|}{ Circulating (anti-) inflammatory factors } \\
\hline $\mathrm{TNF}-\alpha\left(\mathrm{pg} \mathrm{mL} \mathrm{L}^{-1}\right)^{\mathrm{b}}$ & $29(22-56)$ & $65(56-116)^{*}$ \\
\hline Endothelin $1\left(\mathrm{pg} \mathrm{mL}^{-1}\right)^{\mathrm{c}}$ & $27 \pm 2$ & $33 \pm 2 *$ \\
\hline Nitrite + nitrate $\left.(\mu \mathrm{mol} \mathrm{L})^{-1}\right)^{\mathrm{d}}$ & $3.33 \pm 0.52$ & $3.78 \pm 0.89$ \\
\hline \multicolumn{3}{|l|}{ Lung NO system ${ }^{\mathrm{e}}$} \\
\hline eNOS & $0.0027 \pm 0.0006$ & $0.0023 \pm 0.0003$ \\
\hline iNOS & $0.0012(0.0010-0.0025)$ & $0.0019(0.0003-0.0025)$ \\
\hline PDE5 & $0.093(0.072-0.106)$ & $0.122(0.075-0.173)$ \\
\hline \multicolumn{3}{|l|}{ Lung endothelin system ${ }^{\mathrm{e}}$} \\
\hline PPET & $0.020 \pm 0.004$ & $0.032 \pm 0.011$ \\
\hline ECE-1 & $0.023 \pm 0.001$ & $0.028 \pm 0.003$ \\
\hline EDNRA & $0.017(0.013-0.012)$ & $0.017(0.012-0.023)$ \\
\hline EDNRB & $0.048 \pm 0.008$ & $0.039 \pm 0.007$ \\
\hline EDNR A/B ratio & $0.40(0.32-4.2)$ & $0.39(0.30-0.75)$ \\
\hline \multicolumn{3}{|l|}{ Lung antioxidants ${ }^{\mathrm{e}}$} \\
\hline Catalase & $0.132 \pm 0.011$ & $0.185 \pm 0.018^{*}$ \\
\hline SOD1 & $0.340(0.288-0.538)$ & $0.129(0.125-0.167)^{*}$ \\
\hline SOD2 & $0.081(0.071-0.135)$ & $0.066(0.052-0.155)$ \\
\hline SOD3 & $0.063 \pm 0.013$ & $0.039 \pm 0.011$ \\
\hline Glutathione peroxidase & $0.463 \pm 0.085$ & $0.792 \pm 0.133^{(*)}$ \\
\hline
\end{tabular}

Values are mean \pm SEM or median (IQR)

GFR glomerular filtration rate, TNF- $\alpha$ tumor necrosis factor alpha, eNOS endothelial nitric oxide synthase, iNOS inducible nitric oxide synthase, PDE5 phosphodiesterase 5, PPET prepro-endothelin 1, ECE-1 endothelin converting enzyme, EDNRA endothelin receptor A, EDNRB endothelin receptor B, SOD superoxide dismutase

$\left.* P \leq 0.05,{ }^{*}\right) P \leq 0.1$ Healthy vs $\mathrm{DM}+\mathrm{HC}+\mathrm{CKD}$

${ }^{\text {a Healthy }} n=9 \mathrm{DM}+\mathrm{HC}+\mathrm{CKD} n=9$

${ }^{\mathrm{b}}$ Healthy $n=14 \mathrm{DM}+\mathrm{HC}+\mathrm{CKD} n=17$

${ }^{\mathrm{c}}$ Healthy $n=14 \mathrm{DM}+\mathrm{HC}+\mathrm{CKD} n=15$

${ }^{\mathrm{d}}$ Healthy $n=13 \mathrm{DM}+\mathrm{HC}+\mathrm{CKD} n=11$

${ }^{\mathrm{e}}$ Healthy $n=6 \mathrm{DM}+\mathrm{HC}+\mathrm{CKD} n=5$ the relation between mean $\mathrm{PA}$ pressure and $\mathrm{BVO}_{2}$ was similar in $\mathrm{DM}+\mathrm{HC}+\mathrm{CKD}$ swine compared to Healthy swine, the relations between PA pressure and cardiac index, as well as the relation between TPG and cardiac index were shifted upwards, reflecting a higher pulmonary vascular resistance (PVR) in $\mathrm{DM}+\mathrm{HC}+\mathrm{CKD}$ swine, particularly under resting conditions (Fig. 1). This increase in PVR could not be explained by structural pulmonary arterial changes, as pulmonary arterial compliance $(38 \pm 2$ vs.
$37 \pm 3 \mu \mathrm{l} \bullet \mathrm{kg}^{-1} \cdot \mathrm{mmHg}^{-1}$ in Healthy and DM + HC + CKD, respectively) and media-to-lumen ratio in vessels of $\sim 80 \mu \mathrm{m}$ diameter as well as muscularization of vessels ranging 10-30 $\mu \mathrm{m}$ in diameter were similar between Healthy and DM + HC + CKD (Fig. 2), suggesting that the increase in PVR was mediated by functional alterations, i.e. an increase in pulmonary vascular tone. 

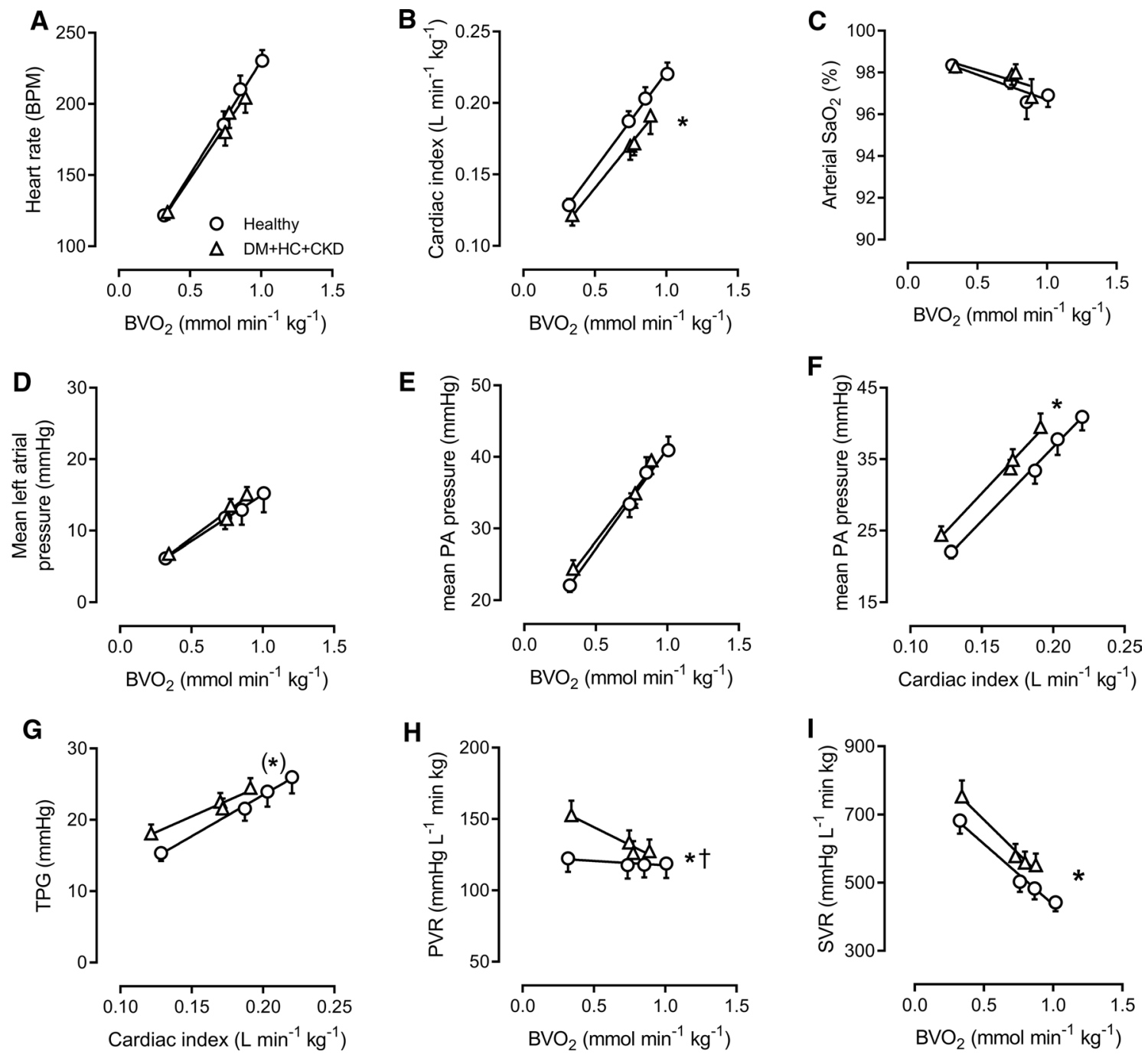

Fig. 1 Pulmonary hemodynamic and function. Heart rates at rest and during exercise were similar between groups (A), cardiac index was lower in $\mathrm{DM}+\mathrm{HC}+\mathrm{CKD}$ compared to Healthy swine (B) for any given level of body oxygen consumption $\left(\mathrm{BVO}_{2}\right)$. Pulmonary function was maintained as oxygen saturation $\left(\mathrm{SaO}_{2}, \mathrm{C}\right)$ was similar between groups. Left atrial pressures were similar between groups, suggesting no left ventricular backward failure (D). Mean pulmonary arterial (PA) pressure was similar for any given level of $\mathrm{BVO}_{2}(\mathbf{E})$, but was

\section{Alterations in pulmonary and systemic vascular tone regulation}

Despite elevated circulating ET-1 levels, $\mathrm{ET}_{\mathrm{A}+\mathrm{B}} \mathrm{i}$ induced similar vasodilation of the systemic vasculature in $\mathrm{DM}+\mathrm{HC}+\mathrm{CKD}$ and Healthy swine (Fig. 3). $\mathrm{ET}_{\mathrm{A}+\mathrm{B}^{\mathrm{i}} \text { with }}$ tezosentan had no effect on PVR in Healthy swine (Fig. 3). In contrast, $\mathrm{ET}_{\mathrm{A}+\mathrm{B}} \mathrm{i}$ resulted in pulmonary vasodilation in $\mathrm{DM}+\mathrm{HC}+\mathrm{CKD}$ swine, as evidenced by a significant decrease in PVR and TPG (Fig. 3). Interestingly, in the presence of $\mathrm{ET}_{\mathrm{A}+\mathrm{B}} \mathrm{i}$, the TPG and PVR values in $\mathrm{DM}+\mathrm{HC}+\mathrm{CKD}$ were similar to the control values and the increased for any given level of filling (F). Transpulmonary gradient (TPG) was also increased for any level of cardiac index (G), resulting in a higher pulmonary vascular resistance (PVR) in DM+ HC + CKD compared to Healthy (H). Systemic vascular resistance (SVR) was higher in DM+HC+CKD compared to Healthy (I). PVRi $n=11$, rest of parameters $n=12$ for both groups. Values are mean \pm SEM. ${ }^{*} P \leq 0.05,{ }^{*} P \leq 0.1$ for Healthy versus $\mathrm{DM}+\mathrm{HC}+\mathrm{CKD},{ }^{\dagger} P \leq 0.05$ for interaction $\mathrm{DM}+\mathrm{HC}+\mathrm{CKD} \times \mathrm{BVO}_{2}$

$\mathrm{ET}_{\mathrm{A}+\mathrm{B}} \mathrm{i}$ values in the Healthy group. These observations indicate that an increased pulmonary vasoconstrictor influence of ET was principally responsible for the increased $\mathrm{PVR}$ in $\mathrm{DM}+\mathrm{HC}+\mathrm{CKD}$. Although the mRNA levels of the $\mathrm{ET}_{\mathrm{A}}$ and $\mathrm{ET}_{\mathrm{B}}$ receptors, prepro-ET-1 and endothelin converting enzyme were unaltered in bulk lung tissue (Table 3), immunohistochemical staining for the $\mathrm{ET}_{\mathrm{B}}$ receptor in a subset of animals showed a reduced $\mathrm{ET}_{\mathrm{B}}$ expression in the pulmonary endothelial cells of $\mathrm{DM}+\mathrm{HC}+\mathrm{CKD}$ swine (Fig. 2). Since the endothelial $\mathrm{ET}_{\mathrm{B}}$ receptor is the main clearance receptor for $\mathrm{ET}$, and its activation induces $\mathrm{NO}$-mediated vasodilation, such reduced $\mathrm{ET}_{\mathrm{B}}$ expression likely contributed 
Fig. 2 Pulmonary vessel structure of $\mathrm{DM}+\mathrm{HC}+\mathrm{CKD}$ and Healthy swine. Typical examples of pulmonary elastin stained (A), lectin and smooth muscle stained $(\mathbf{C})$, Endothelin $\mathrm{B}\left(\mathrm{ET}_{\mathrm{B}}\right)$ receptor stained $(\mathbf{E})$ and hematoxylin-eosin stained (G) sections. Wall-to-lumen ratio of pulmonary arterioles (B) and muscularization of small $(10-30 \mu \mathrm{m})$ pulmonary vessels $(0-$ non-muscularized; 1,2,3-partially muscularized and 4-fully muscularized) (D) was not different between groups. Number of quadrants stained for the endothelin B $\left(\mathrm{ET}_{\mathrm{B}}\right)$ receptor in the pulmonary endothelium of arterioles (20-60 $\mu \mathrm{m})$ were lower $(\mathbf{F})$ and perivascular inflammation score tended to be lower $(\mathbf{H})$ in $\mathrm{DM}+\mathrm{HC}+\mathrm{CKD}$ compared to Healthy $(\mathbf{H})$. Black arrows show scored quadrants in panel $\mathbf{C}$ and $\mathbf{E}$, white arrows represent unscored quadrants. Values are mean \pm SEM (solid line for panel $\mathbf{B}, \mathbf{D}$ and $\mathbf{F}$ ), or median \pm IQR (dashed line for panel $\mathbf{H}) * P \leq 0.05$, ${ }^{(*)} P \leq 0.10$ for Healthy versus $\mathrm{DM}+\mathrm{HC}+\mathrm{CKD}$
A

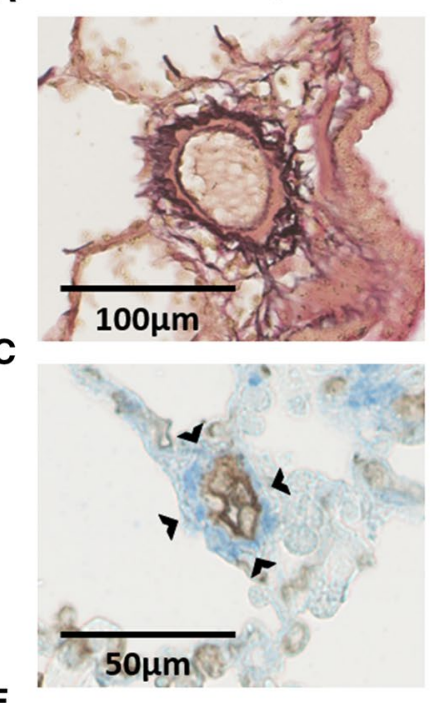

E

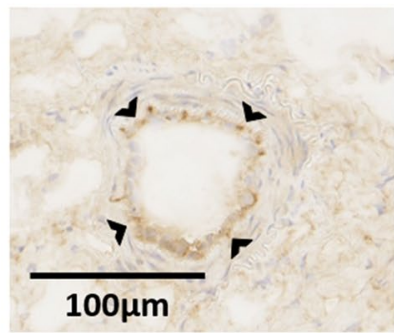

G

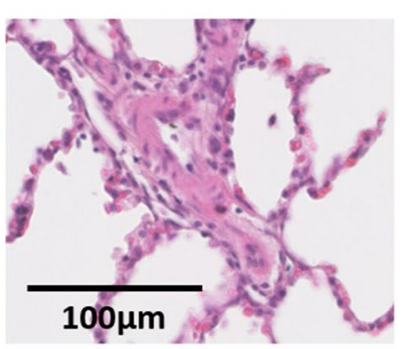

$\mathrm{DM}+\mathrm{HC}+\mathrm{CKD}$
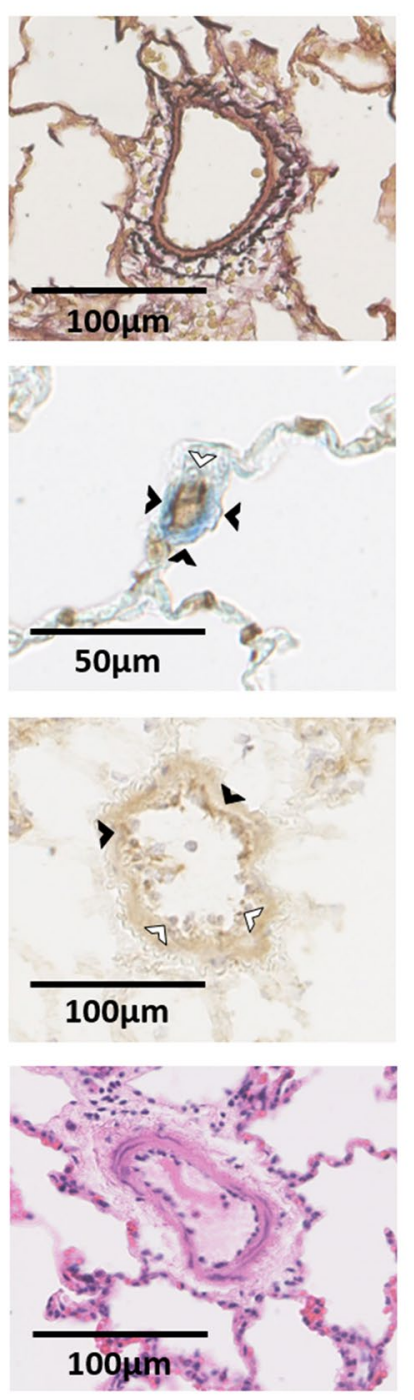

B

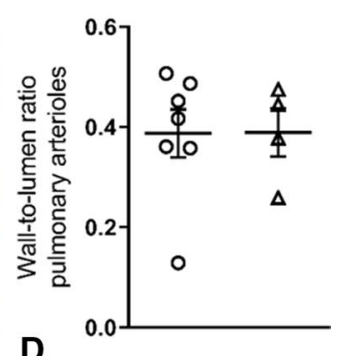

D
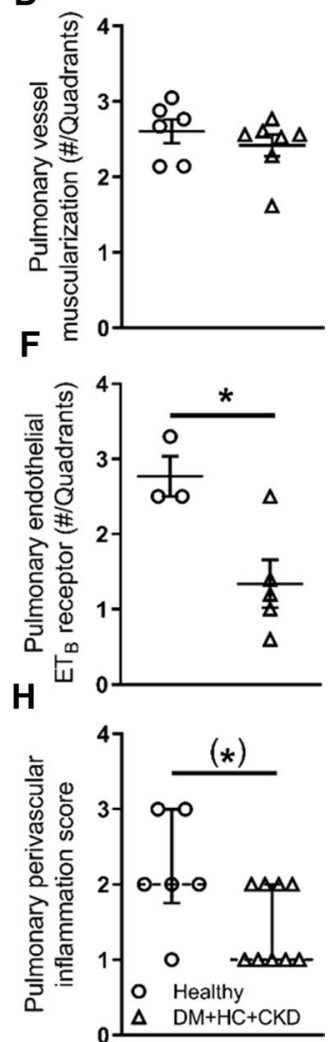

to the enhanced circulating ET-levels and ET-mediated pulmonary vasoconstrictor influence.

NOSi markedly increased TPG while decreasing cardiac output at rest, reflecting an increase in PVR, this effect being similar in Healthy and DM + HC + CKD swine (Fig. 4). The increase in PVR induced by NOSi was slightly attenuated during exercise in $\mathrm{DM}+\mathrm{HC}+\mathrm{CKD}$ but not Healthy swine (Fig. 4). The maintained vasodilator influence of endogenous $\mathrm{NO}$ was consistent with the unaltered eNOS protein levels, eNOS uncoupling (monomer/ dimer ratio) and eNOS phosphorylation as well as with the unaltered phosphorylated VASP/VASP ratio in lung tissue, which reflects similar PKG activity between groups (Fig. 5). Furthermore, iNOS mRNA was unchanged and approximately threefold lower than eNOS mRNA levels (Table 3). However, several important anti-oxidant systems were affected by $\mathrm{DM}+\mathrm{HC}+\mathrm{CKD}$, with increased catalase and glutathione peroxidase mRNA expression, but decreased superoxide dismutase 1 (SOD1) expression in the lungs of $\mathrm{DM}+\mathrm{HC}+\mathrm{CKD}$ swine (Table 3 ). This was accompanied by a trend towards a decrease in pulmonary perivascular inflammation score (Fig. 2). ROS scavenging with a combination of MPG and Tempol did not result in changes in PVR in either Healthy or $\mathrm{DM}+\mathrm{HC}+\mathrm{CKD}$ swine at rest or during exercise (Fig. 6), suggesting that ROS do not influence pulmonary vascular tone in this model. Conversely, ROS scavenging did induce systemic vasodilation in DM + HC + CKD but not Healthy swine (Fig. 6). Furthermore, NOSi induced more vasoconstriction in the systemic circulation in $\mathrm{DM}+\mathrm{HC}+\mathrm{CKD}$ compared to Healthy swine (Fig. 4).

The NO and the ET-pathways interact with each other at multiple levels, i.e. activation of $\mathrm{ET}_{\mathrm{B}}$ receptors on endothelial cells results in NO production and NO suppresses ET production and release, both resulting in NO interfering with ET-mediated vasoconstriction. Hence, $\mathrm{ET}_{\mathrm{A}+\mathrm{B}} \mathrm{i}$ was repeated in the presence of NOSi. Following $\mathrm{NOSi}, \mathrm{ET}_{\mathrm{A}+\mathrm{B}} \mathrm{i}$ 


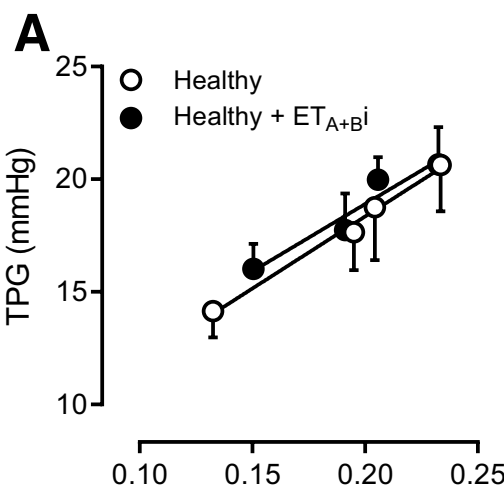

Cardiac index $\left(\mathrm{L} \mathrm{min}^{-1} \mathrm{~kg}^{-1}\right)$

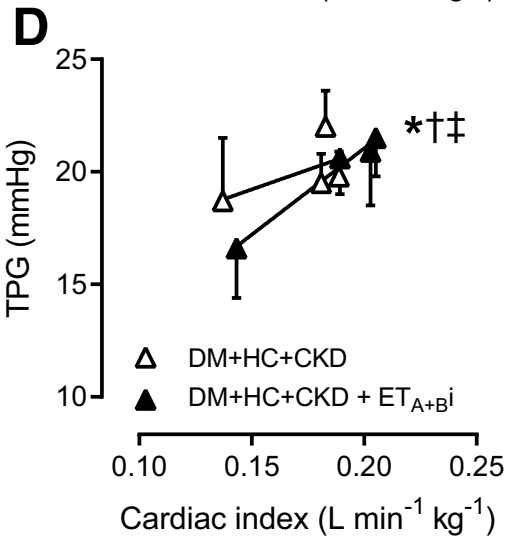

B

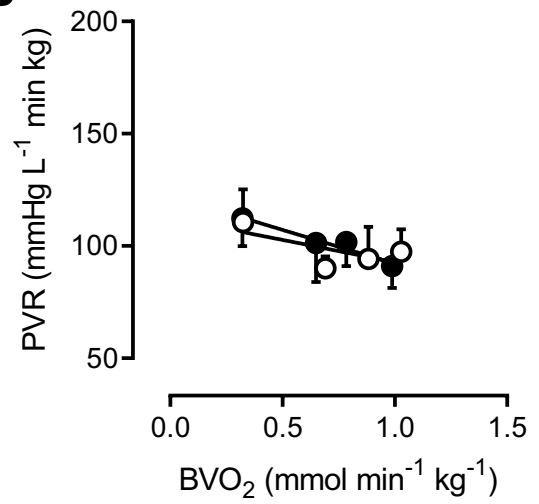

E

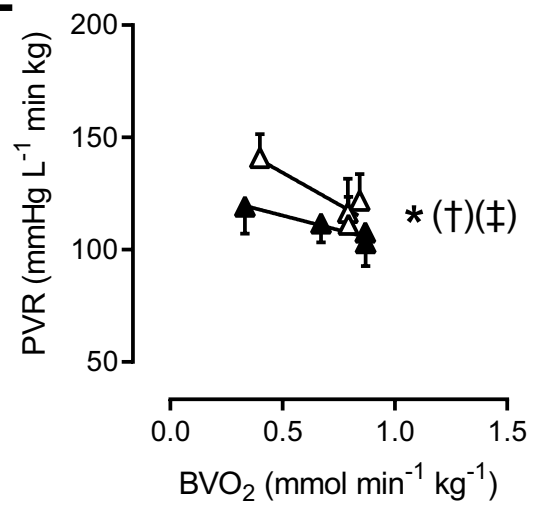

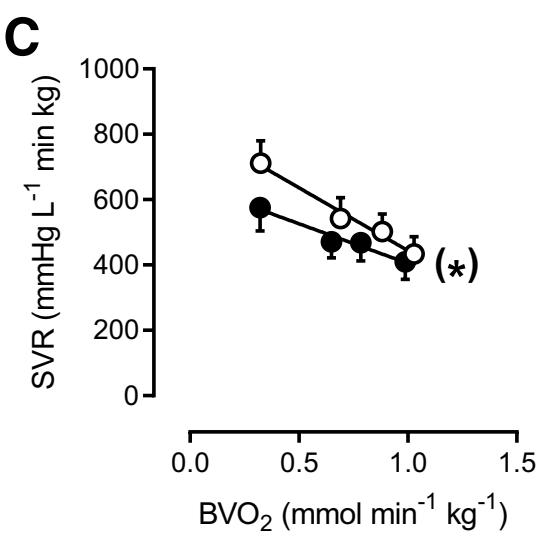

$\mathbf{F}$

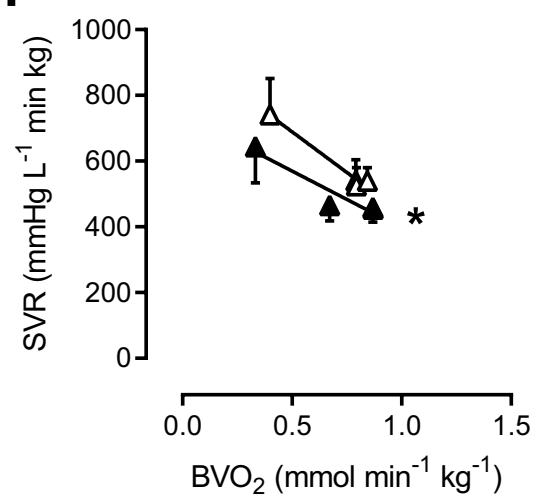

Fig. 3 Role of the endothelin-pathway in pulmonary and systemic vasomotor control in $\mathrm{DM}+\mathrm{HC}+\mathrm{CKD}$ and Healthy swine. Transpulmonary gradient (TPG) as a function of cardiac index during graded exercise showed no significant change in response to endothelin receptor $\mathrm{A}$ and $\mathrm{B}$ blockade $\left(\mathrm{ET}_{\mathrm{A}+\mathrm{B}} \mathrm{i}\right)$ in Healthy $(\mathrm{A})$ but did decrease slightly in $\mathrm{DM}+\mathrm{HC}+\mathrm{CKD}$ (D) swine particularly at rest. Pulmonary vascular resistance (PVR) was unchanged in response to $\mathrm{ET}_{\mathrm{A}+\mathrm{B}} \mathrm{i}$ in Healthy $(\mathbf{B})$, while $\mathrm{DM}+\mathrm{HC}+\mathrm{CKD}$ showed pulmonary

decreased SVR in DM $+\mathrm{HC}+\mathrm{CKD}$ but not Healthy swine, which suggests that, indeed, increased ET-mediated systemic vasoconstriction contributed to the larger increase in SVR in response to NOSi in DM $+\mathrm{HC}+\mathrm{CKD}$ (Fig. 7).

In the pulmonary vasculature of Healthy swine, NOSi unmasked a vasodilator effect of $\mathrm{ET}_{\mathrm{A}+\mathrm{B}} \mathrm{i}$, as evidenced by marked reductions in TPG and PVR at rest and during exercise (Fig. 7). In swine with $\mathrm{DM}+\mathrm{HC}+\mathrm{CKD}$, $\mathrm{ET}_{\mathrm{A}+\mathrm{B}} \mathrm{i}$ did not result in a statistically significant change in PVR in the presence of NOSi (Fig. 7). Together with the reduced endothelial $\mathrm{ET}_{\mathrm{B}}$ receptor expression in the lung of $\mathrm{DM}+\mathrm{HC}+\mathrm{CKD}$ (Fig. 2), these data imply that in Healthy swine, the $\mathrm{ET}_{\mathrm{B}}$ receptor activates $\mathrm{NO}$ production, thereby suppressing the pulmonary vasoconstrictor influence of ET, and that this effect is lost in $\mathrm{DM}+\mathrm{HC}+\mathrm{CKD}$ swine.

Further downstream in the NO-pathway, inhibition of PDE5 acts to prolong the half-life of cGMP. Despite an unaltered PDE5 mRNA expression in lung tissue (Table 3), vasodilation in response to $\mathrm{ET}_{\mathrm{A}+\mathrm{B}} \mathrm{i}(\mathbf{E}) \cdot \mathrm{ET}_{\mathrm{A}+\mathrm{B}^{\mathrm{i}}} \mathrm{r}$ resulted in similar reduction in systemic vascular resistance (SVR) in Healthy and $\mathrm{DM}+\mathrm{HC}+\mathrm{CKD}(\mathbf{C}, \mathbf{F})$. Healthy $n=6, \mathrm{DM}+\mathrm{HC}+\mathrm{CKD} n=6$. Values are mean \pm SEM. ${ }^{*} P \leq 0.05,{ }^{(*)} P \leq 0.1$ for effect $\mathrm{ET}_{\mathrm{A}+\mathrm{B}} \mathrm{i}$ within group, ${ }^{\dagger} P \leq 0.05$, ${ }^{(\dagger)} P \leq 0.10$ for interaction $\mathrm{ET}_{\mathrm{A}+\mathrm{B}} \mathrm{i} \times$ cardiac index (C) or $\mathrm{ET}_{\mathrm{A}+\mathrm{B}} \mathrm{i} \times \mathrm{BVO}_{2}$ (D) within groups, ${ }^{\ddagger} P \leq 0.05$, ${ }^{(\ddagger)} P \leq 0.10$ for interaction $\mathrm{ET}_{\mathrm{A}+\mathrm{B}} \mathrm{i} \times$ group

PDE5i decreased TPG and PVR in DM $+\mathrm{HC}+\mathrm{CKD}$ swine but not in Healthy swine (Fig. 8), both at rest and during exercise. The increased vasoconstrictor influence of PDE5 in the pulmonary vasculature likely also contributed to the increased PVR in DM + HC + CKD swine. In contrast, the reduction in SVR with PDE5i was similar between groups (Fig. 8).

\section{Right ventricular function and structure}

In accordance with the unaltered PA pressure, pulmonary vascular elastance $(\mathrm{Ea})$, a measure of RV afterload was not changed in $\mathrm{DM}+\mathrm{HC}+\mathrm{CKD}$ (Fig. 9). RV systolic and diastolic functions were maintained in $\mathrm{DM}+\mathrm{HC}+\mathrm{CKD}$ and $\mathrm{RV}$ diastolic and systolic volumes were also unaltered (Fig. 9).

Histological examination of the RV revealed subtle changes in the structure of the RV. Interestingly, the cross-sectional area of the cardiomyocytes was 
A

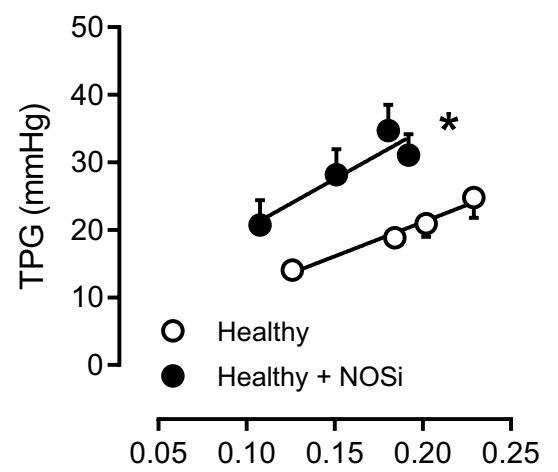

Cardiac index $\left(\mathrm{L} \mathrm{min}^{-1} \mathrm{~kg}^{-1}\right)$

D

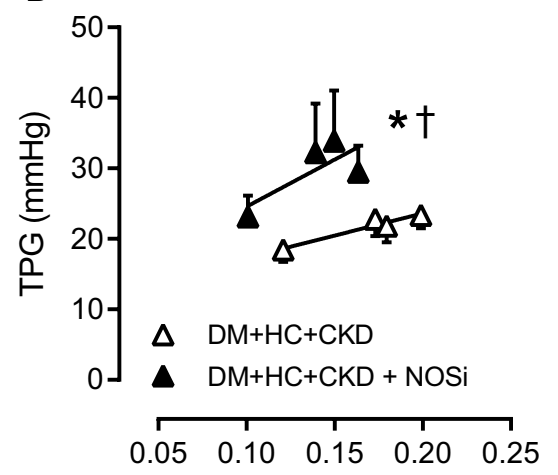

Cardiac index $\left(\mathrm{L} \mathrm{min}^{-1} \mathrm{~kg}^{-1}\right)$
B

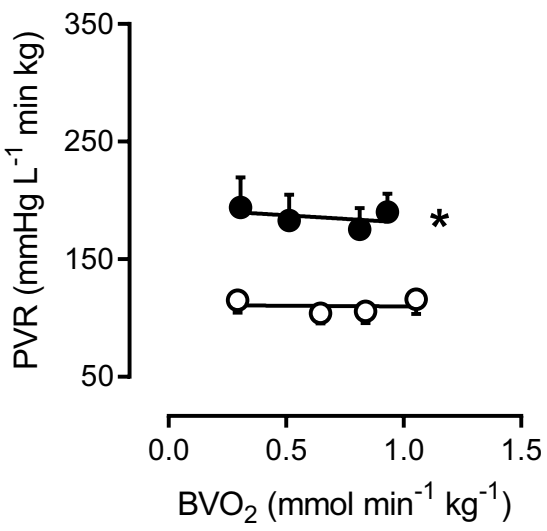

E

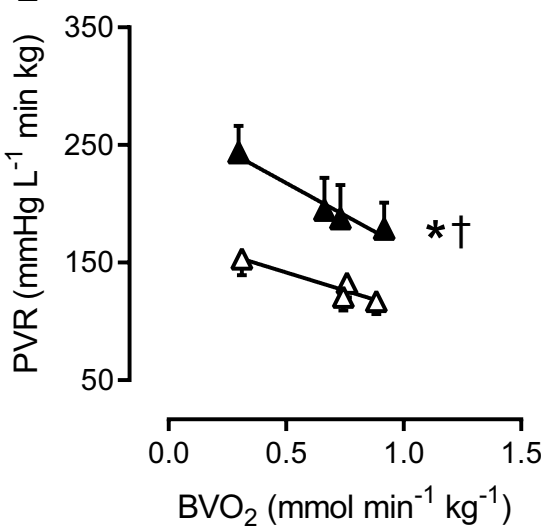

C

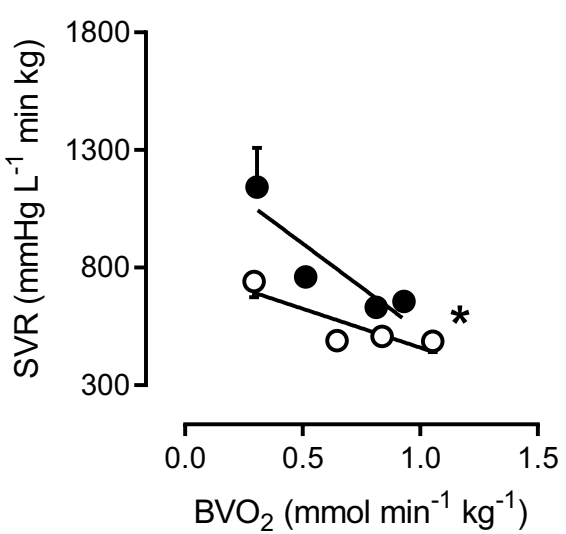

$\mathbf{F}$

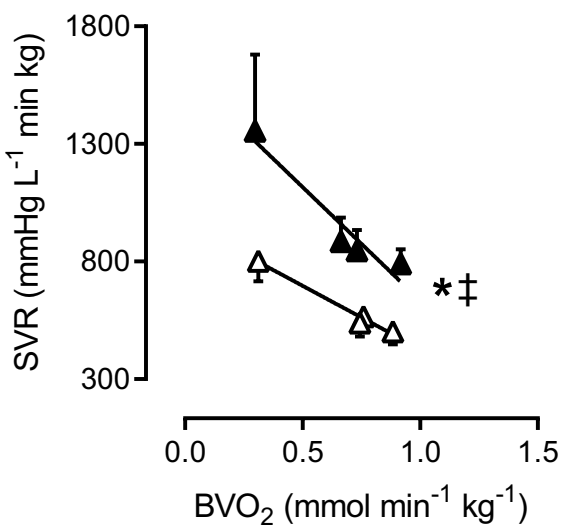

Fig. 4 Nitric oxide in pulmonary and systemic vasomotor control in $\mathrm{DM}+\mathrm{HC}+\mathrm{CKD}$ and Healthy swine. Transpulmonary gradient (TPG) as a function of cardiac index markedly increased as a result of endothelial nitric oxide synthase inhibition (NOSi) in both Healthy (A) and $\mathrm{DM}+\mathrm{HC}+\mathrm{CKD}$ (D) both at rest and during exercise. NOSi resulted in a similar increase in pulmonary vasoconstriction, as evidenced by the increase in pulmonary vascular resistance (PVR), in

decreased in DM + HC + CKD compared to Healthy swine (Fig. 10). Absolute RV weights were also lower in $\mathrm{DM}+\mathrm{HC}+\mathrm{CKD}$ than Healthy swine (Fig. 10), while relative RV weight to total heart weight (Healthy $0.29 \pm 0.01$ vs $\mathrm{DM}+\mathrm{HC}+\mathrm{CKD} 0.27 \pm 0.01, P=0.196)$ and the Fulton index (Healthy $0.42 \pm 0.02$ vs DM $+\mathrm{HC}+\mathrm{CKD}$ $0.37 \pm 0.02, P=0.177$ ) were unchanged. Additionally, capillary density was similar in both groups (Fig. 10). In line with these findings, combination with the cell count of the cardiomyocytes revealed a decreased capillary-to-fiber ratio in $\mathrm{DM}+\mathrm{HC}+\mathrm{CKD}$ compared to Healthy controls (Fig. 10). The total collagen content of the RV was similar between the groups, however, a shift of the collagen type composition of the RV towards more compliant type III collagen was observed (Fig. 10).
Healthy (B) and DM $+\mathrm{HC}+\mathrm{CKD}$ swine (E). Nitric oxide synthase inhibition (NOSi) has a more pronounced effect on systemic vascular resistance (SVR) in DM $+\mathrm{HC}+\mathrm{CKD}(\mathbf{F})$ than in Healthy swine $(\mathbf{C})$. Healthy $n=7, \mathrm{DM}+\mathrm{HC}+\mathrm{CKD} n=7$ at rest and $n=5$ during exercise. Values are mean \pm SEM. $* P \leq 0.05$ for effect NOSi within group, ${ }^{\dagger} P \leq 0.05$ for interaction NOSi $\times$ cardiac index (D) or $\mathrm{NOSi} \times \mathrm{BVO}_{2}$ (E) within group. ${ }^{\ddagger} P \leq 0.05$ for interaction $\mathrm{NOSi} \times$ group $(\mathbf{F})$

\section{Discussion}

The present study tested the hypothesis that in a swine model with multiple comorbidities and left ventricular diastolic dysfunction, in the absence of overt left ventricular backward failure, multiple comorbidities result in functional pulmonary vascular alterations in exercising swine. The main findings were that (i) the combination of DM, HC and CKD resulted in increased systemic and pulmonary vascular resistance. (ii) The increase in pulmonary vascular resistance was principally due to changes in pulmonary vasomotor control in the absence of pulmonary vascular structural changes. (iii) $\mathrm{ET}_{\mathrm{A}+\mathrm{B}} \mathrm{i}$ as well as PDE5i reduced PVR in $\mathrm{DM}+\mathrm{HC}+\mathrm{CKD}$ but not in Healthy swine. (iv) The increase in PVR in response to NOSi was similar in $\mathrm{DM}+\mathrm{HC}+\mathrm{CKD}$ compared to Healthy swine, with unaltered eNOS protein, phosphorylation and uncoupling. Furthermore, eNOSi unmasked a vasodilator effect of subsequent $\mathrm{ET}_{\mathrm{A}+\mathrm{B}} \mathrm{i}$ in 
A

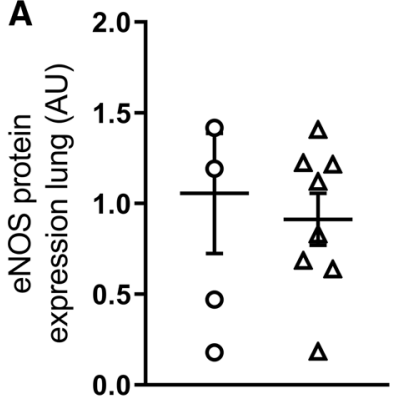

C

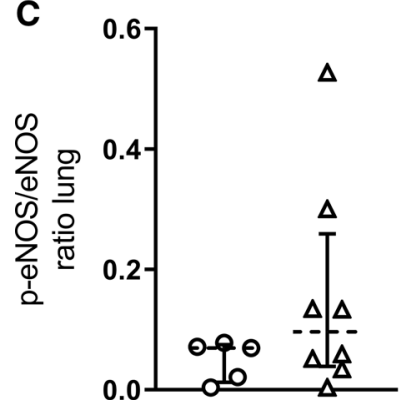

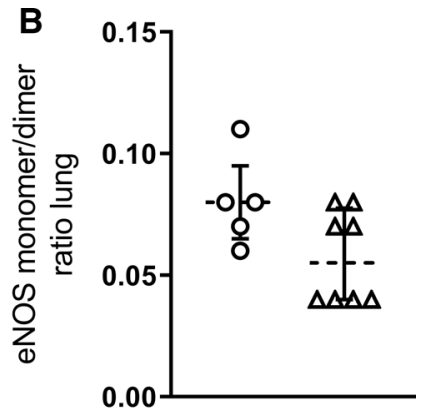

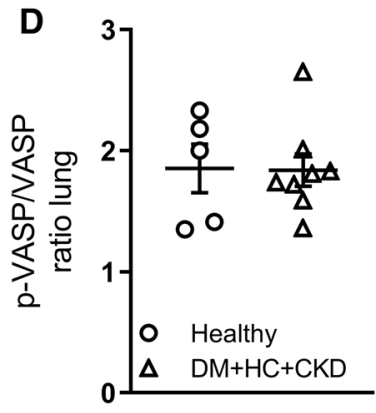

Fig. 5 Endothelial nitric oxide (eNOS) pathway activity patterns in bulk lung tissue of DM $+\mathrm{HC}+\mathrm{CKD}$ and Healthy, detected by Western blots. Total eNOS protein (A), eNOS monomer/dimer ratios (B), phosphorylated eNOS/eNOS ratios (C) and phosphorylated VASP/ VASP ratios (D) were unchanged in $\mathrm{DM}+\mathrm{HC}+\mathrm{CKD}$ compared to Healthy. Values are mean \pm SEM (solid lines, panel $\mathbf{A}$ and $\mathbf{D}$ ) or median \pm IQR (dashed lines, panel $\mathbf{B}$ and $\mathbf{C}$ ). Uncut Western blots are provided in the supplemental data file

Healthy swine, but not in $\mathrm{DM}+\mathrm{HC}+\mathrm{CKD}$ swine, consistent with the observed loss of pulmonary endothelial $\mathrm{ET}_{\mathrm{B}}$ receptors. (v) ROS scavenging did not induce pulmonary vasodilation in either DM $+\mathrm{HC}+\mathrm{CKD}$ or Healthy swine. The implications of these findings are discussed below with a focus on PVD as an early complication of DM $+\mathrm{HC}+\mathrm{CKD}$.

\section{Methodological considerations}

$\mathrm{HFpEF}$ is a heterogeneous disorder resulting from various combinations of underlying comorbidities that is more prevalent in women [10, 43]. To resemble the clinical pathogenesis of HFpEF, the current study was performed in female swine with multiple common comorbidities. Swine have been utilized in multiple investigations concerning metabolic derangement as lipid and glucose metabolism resemble that in humans, with comparable triglycerides levels in high-fat diet induced hypercholesterolemia [2]. Additionally, repeated streptozotocin injections induced hyperglycemia without insulin-dependency mimicking a late-type 2 DM with insulin resistance as seen in patients [55]. Renal dysfunction is present in approximately $50 \%$ of HFpEF patients and diastolic dysfunction is one of the first observed cardiovascular alterations in patients with early-stage CKD [54]. In the present study, CKD was induced by embolizing $~ 3 / 4$ of the kidneys and resulted in a $30 \%$ decrease in renal function mimicking an early stage of CKD. Our findings, which indicate that PVD is already present in swine after 5-6 months of exposure to multiple comorbiditiesincluding CKD — are in accordance with two studies using unsupervised phenomapping of a large group of patients clinically diagnosed with HFpEF [47, 61]. This phenomapping resulted in three or four main phenotypes, in which the presence of CKD clustered with RV dilation and high pulmonary pressures in the group with the worst prognosis [47, 61]. Moreover, the fact that renal dysfunction, pulmonary and peripheral vascular alterations in HFpEF were recently prioritized on the research agenda for the coming decade by the National Heart, Lung, and Blood Institute Working Group on HFpEF [46], underscores the value of animal models to further study their interaction. Our early observations warrant future studies in swine using longer periods of follow-up to investigate whether the PVD already found in the present study at 6 months, progresses to overt pulmonary hypertension and right heart failure.

One aspect of HFpEF that was not accounted for in the present study, is that HFpEF is predominantly present in older post-menopausal women. Indeed, sex-differences and sex-hormones are well-known to play a role in the regulation of vascular tone as well as in the development and progression of cardiovascular disease [45], and differences in the ET system have been proposed to play a role in this sexual dimorphism. Thus, premenopausal women have lower circulating ET-levels as compared to age matched men, but ETlevels increase after menopause, which has been ascribed to estrogen stimulating eNOS, which in turn inhibits the ET system [20]. In addition, the ratio of vasodilator $\mathrm{ET}_{\mathrm{B}}$ receptors to vasoconstrictor $\mathrm{ET}_{\mathrm{A}}$ receptors is higher in women as compared to men, and $\mathrm{ET}_{\mathrm{A}}$-mediated vasoconstriction is less pronounced in the forearm of women than men [20]. Future studies should be performed to investigate whether PVD might be aggravated in older and/or ovariectomized swine with multiple comorbidities, and the role of NO- and ET-systems in such potential aggravation.

\section{Pulmonary vascular disease: an early complication of HFpEF and CKD}

The importance of early detection of PVD in various pathologies is increasingly recognized. In pulmonary arterial hypertension, the threshold for PH has recently been lowered from 25 to $20 \mathrm{mmHg}$ [49], as multiple studies showed a higher mortality in patients exhibiting what has previously been described as borderline $\mathrm{PH}(20-25 \mathrm{mmHg})$, as well as in patients with PA pressures in the upper normal range at rest $(17-19 \mathrm{mmHg})[3,11]$. In other forms of $\mathrm{PH}$, such as 


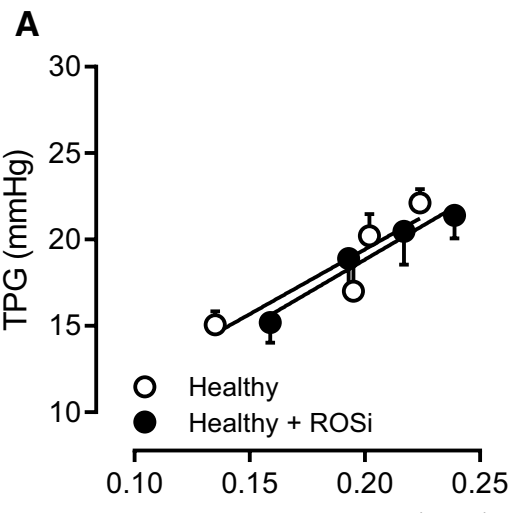

Cardiac index $\left(\mathrm{L} \mathrm{min}^{-1} \mathrm{~kg}^{-1}\right)$

D

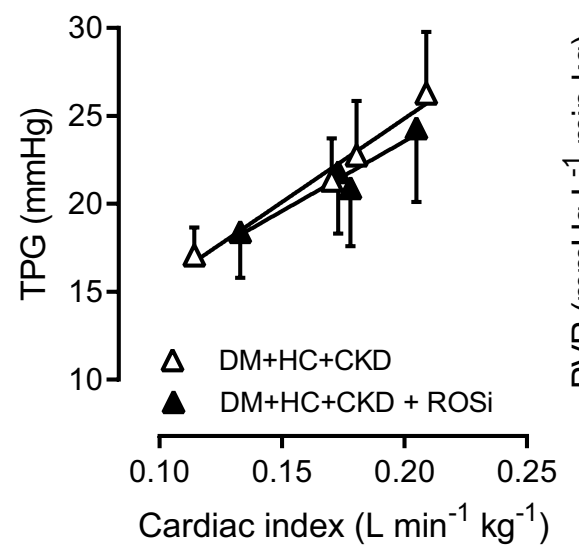

B

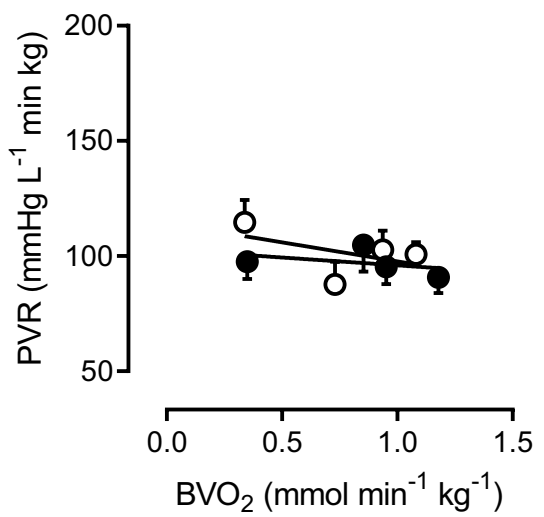

E

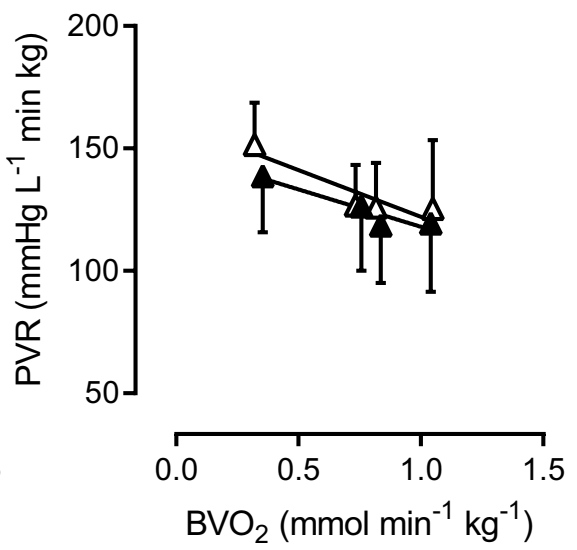

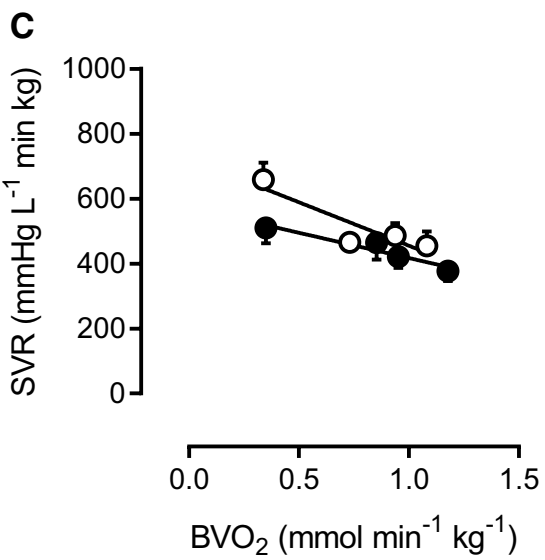

$\mathbf{F}$

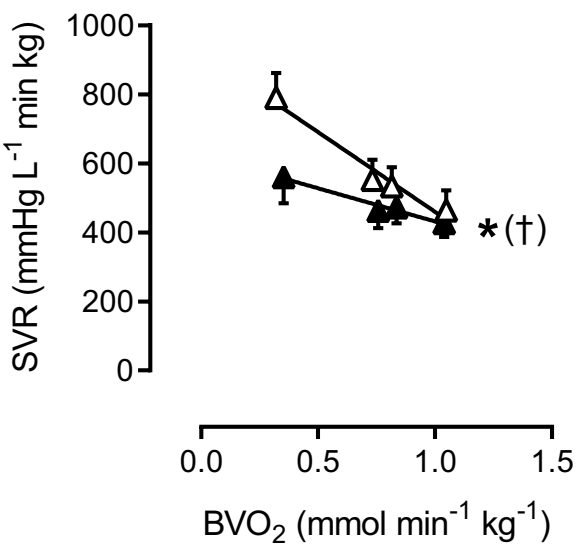

Fig. 6 Role of scavenging of reactive oxygen species (ROSi) in pulmonary and systemic vasomotor control in $\mathrm{DM}+\mathrm{HC}+\mathrm{CKD}$ and Healthy swine. Transpulmonary gradient (TPG) as a function of cardiac index did not result in significant change after ROSi in both Healthy (A) and in DM + HC + CKD (D). Pulmonary vascular resistance (PVR) showed no response to ROSi in Healthy (B), and

HFpEF-associated $\mathrm{PH}$, the debate is ongoing as to whether or not to shift the threshold of PH, since elevations in PA pressure are not solely due to PVD [31, 49]. Nevertheless, also in the HFpEF population, dyspnea was observed prior to pulmonary venous congestion [32], consistent with a precapillary PH-phenotype, and hence with the occurrence of PVD as an initiating factor. One of the earliest signs of PVD in these patients is an exaggerated increase in PA pressure during stress, which is out of proportion with the increases in left atrial pressure and cardiac output, and reflects the inability to decrease PVR during exercise $[21,31]$.

In our study, the relation between cardiac index and PA pressure was shifted upwards due to an increased TPG, and PVR was higher at all levels of exercise in swine with $\mathrm{DM}+\mathrm{HC}+\mathrm{CKD}$ as compared to Healthy swine at a time that left atrial pressure was not affected, suggesting microvascular alterations in the pulmonary vasculature. Interestingly, our data show that PVD, evidenced by the elevated in $\mathrm{DM}+\mathrm{HC}+\mathrm{CKD}(\mathbf{E})$. In the systemic vasculature, no effect of ROSi was observed in Healthy $(\mathbf{C})$, but resulted in vasodilatation in $\mathrm{DM}+\mathrm{HC}+\mathrm{CKD}(\mathbf{F})$ at rest, while this effect was lost during exercise. Healthy $n=8, \mathrm{DM}+\mathrm{HC}+\mathrm{CKD} n=8$. Values are mean $\pm \mathrm{SEM}$. $* P \leq 0.05$ for effect ROSi within group, ${ }^{(\dagger)} P \leq 0.10$ for interaction $\mathrm{ROSi} \times \mathrm{BVO}_{2}$ within group

PVR, is present even before the increase in SVR and the presence of left ventricular diastolic dysfunction resulting in overt elevations in left atrial pressure or PA pressure. However, already at this time point, a more generalized microvascular dysfunction is present as we have recently shown in this porcine model that coronary microvascular function is also impaired [55].

The increased PVR was accompanied by higher circulating levels of TNF- $\alpha$ and ET-1, further reflecting inflammation and endothelial dysfunction. The higher PVR, in the absence of an increase in PA pressure, seems to be in contrast with the general assumption that HFpEF-PH progresses from isolated post-capillary $\mathrm{PH}$ due to left ventricular dysfunction, to pre- and post-capillary PH [31, 33]. Although PVD is highly prevalent in HFpEF and increases morbidity and mortality [22, 31], HFpEF patients form a heterogeneous population, with various underlying conditions-such as DM, HC and/or CKD-leading to 

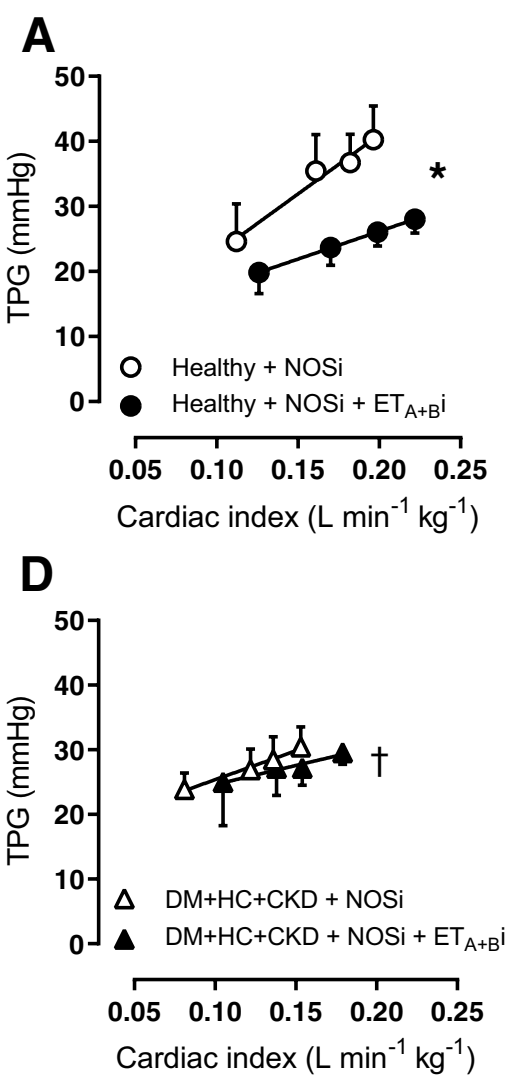

B

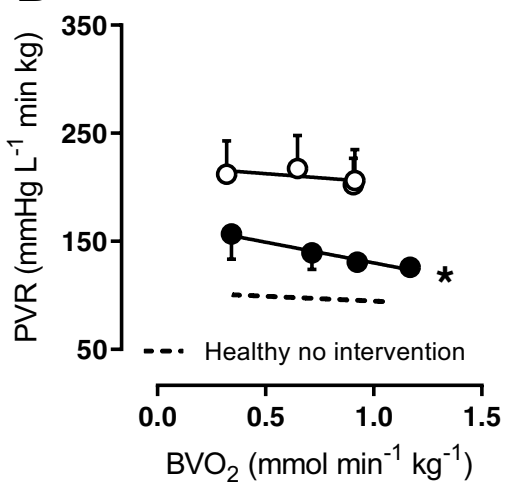

E

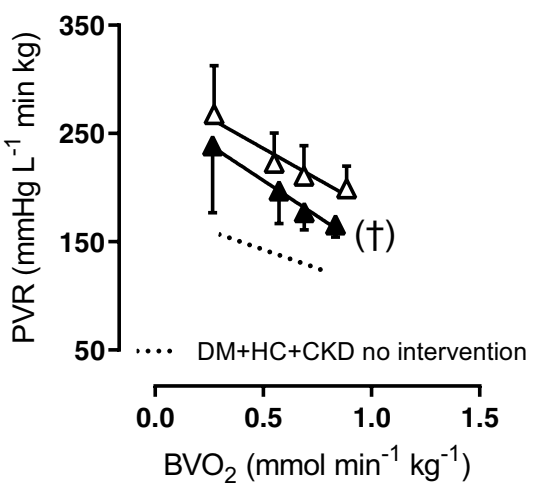

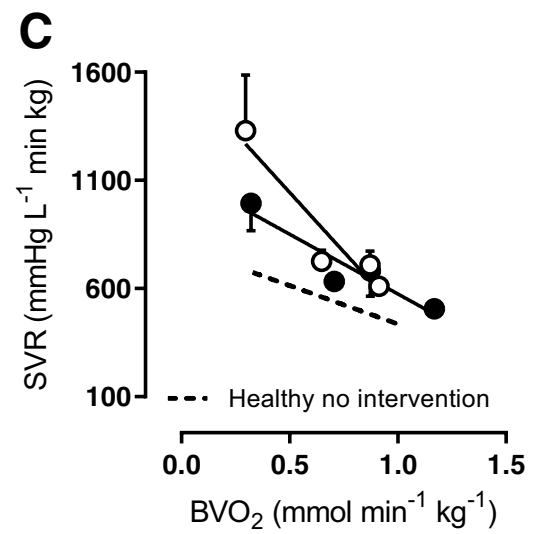

$\mathbf{F}$

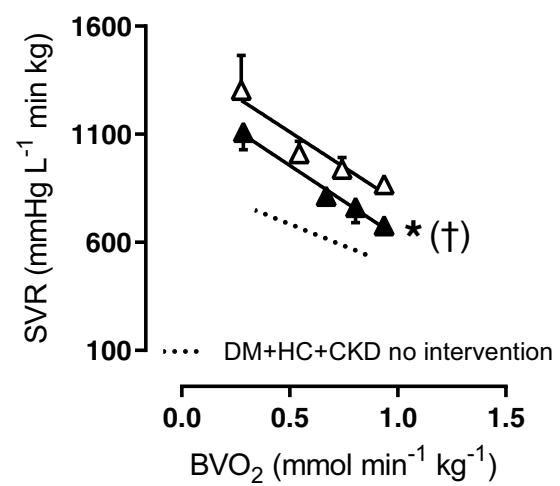

Fig. 7 Role of Endothelin 1 after eNOS inhibition in pulmonary and systemic vasomotor control in $\mathrm{DM}+\mathrm{HC}+\mathrm{CKD}$ and Healthy swine. Transpulmonary gradient (TPG) as a function of cardiac index decreased significantly after endothelin receptor $\mathrm{A}$ and $\mathrm{B}$ inhibition $\left(\mathrm{ET}_{\mathrm{A}+\mathrm{B}} \mathrm{i}\right)$ in the presence of NOS inhibition (NOSi) in Healthy (A) but not in $\mathrm{DM}+\mathrm{HC}+\mathrm{CKD}$ (D). Pulmonary vascular resistance (PVR) decreased significantly in response to $\mathrm{ET}_{\mathrm{A}+\mathrm{B}} \mathrm{i}$ after NOSi in

inflammation and oxidative stress, making some patients more prone to develop combined pre-and post-capillary $\mathrm{PH}$ than others. Especially in HFpEF patients suffering from CKD ( 50\% of the HFpEF patients) [52, 54], microvascular dysfunction is partly mediated by overlapping risk factors such as DM and hypertension, but, importantly, uremic toxins can also directly impact the heart and vasculature, making CKD an independent risk factor for HFpEF development $[52,54]$ as well as for development of PVD and PH $[6,51]$. Together with our data these associations suggest that PVD may develop in a subgroup of patients with left ventricular diastolic dysfunction and CKD, prior to and/or independent of increased left atrial pressures. As no overt perivascular inflammation was present in the lungs, and pulmonary vascular muscularization was unaltered, our data suggest that functional and not structural alterations in the pulmonary vasculature are among the first signs of PVD.
Healthy $(\mathbf{B})$, while in $\mathrm{DM}+\mathrm{HC}+\mathrm{CKD}(\mathbf{E}) \mathrm{ET}_{\mathrm{A}+\mathrm{B}^{\mathrm{i}}}$ additional to NOSi did not result in pulmonary vasodilation. In the systemic vasculature, effect of $\mathrm{ET}_{\mathrm{A}+\mathrm{B}} \mathrm{i}$ during NOSi was only observed at rest in Healthy $(\mathbf{C})$, but resulted in vasodilatation at rest and during exercise in $\mathrm{DM}+\mathrm{HC}+\mathrm{CKD}(\mathbf{F})$. Healthy $n=6, \mathrm{DM}+\mathrm{HC}+\mathrm{CKD} n=4$. Values are mean \pm SEM. ${ }^{*} P \leq 0.05$ for effect $\mathrm{ET}_{\mathrm{A}+\mathrm{B}} \mathrm{i}$ within group, ${ }^{\dagger} P \leq 0.05,\left({ }^{\dagger}\right) P \leq 0.10$ for interaction $\mathrm{ET}_{\mathrm{A}+\mathrm{B}} \mathrm{i} \times$ group

\section{Endothelial dysfunction in early PVD}

PVD is characterized by endothelial dysfunction, impaired pulmonary vasomotor control and vascular remodeling. Endothelial dysfunction involves an imbalance between the ET and NO pathways, which may alter pulmonary vascular control. In the current study, the endogenous vasodilator influence of $\mathrm{NO}$ was unaltered in the pulmonary vasculature as NOSi resulted in a similar vasoconstrictor response in $\mathrm{DM}+\mathrm{HC}+\mathrm{CKD}$ and Healthy swine. These data are consistent with previous findings from our laboratory, showing that the response to NOSi was maintained in swine with PVD secondary to myocardial infarction $[37,56]$ and even increased in PVD secondary to pulmonary vein stenosis [58]. In accordance with the maintained vasodilator influence of endogenous NO in the present study, eNOS mRNA, eNOS total protein, uncoupling and phosphorylation were unaltered in $\mathrm{DM}+\mathrm{HC}+\mathrm{CKD}$. Also, phosphorylated VASP/ 


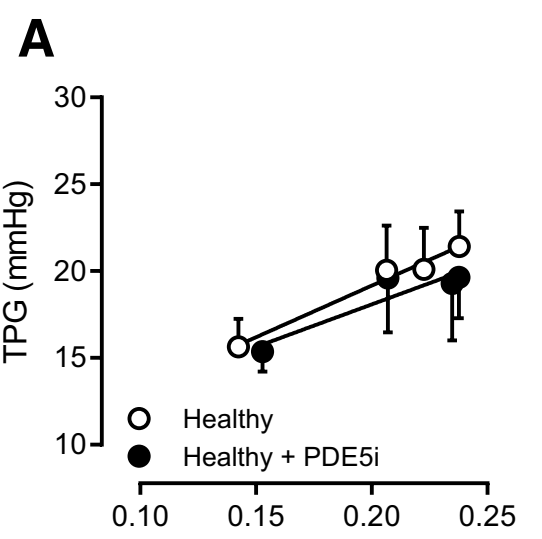

Cardiac index $\left(\mathrm{L} \mathrm{min}^{-1} \mathrm{~kg}^{-1}\right)$

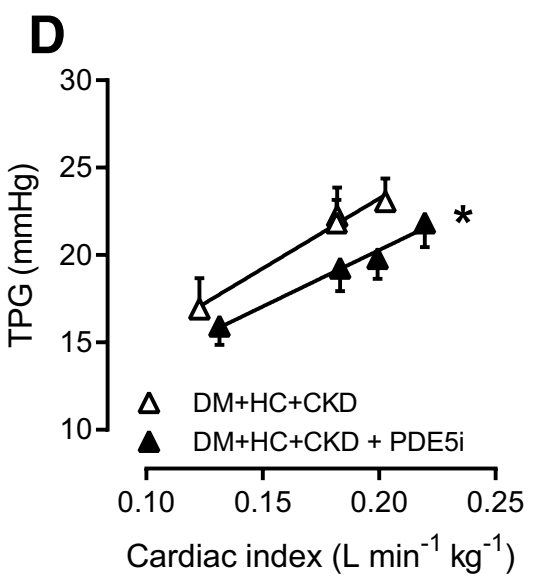

B

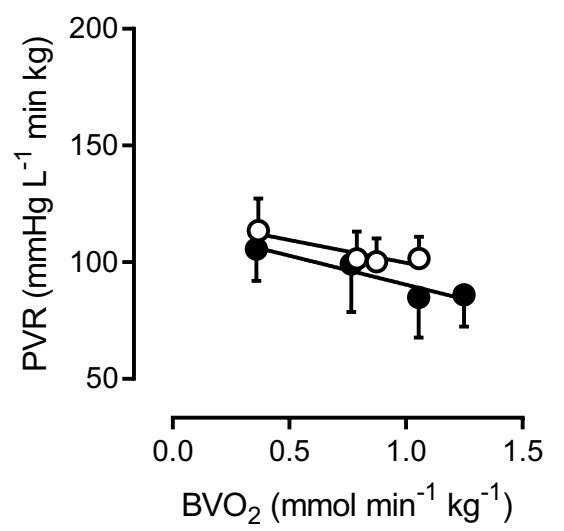

E

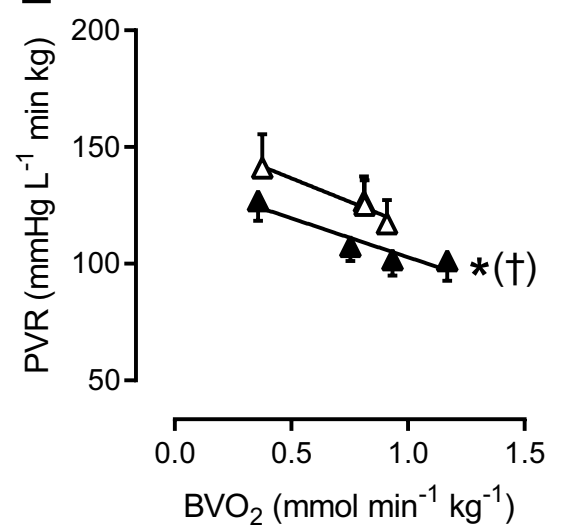

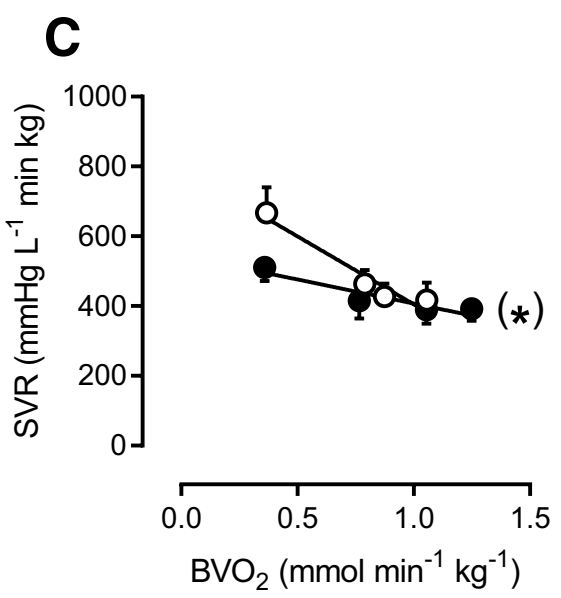

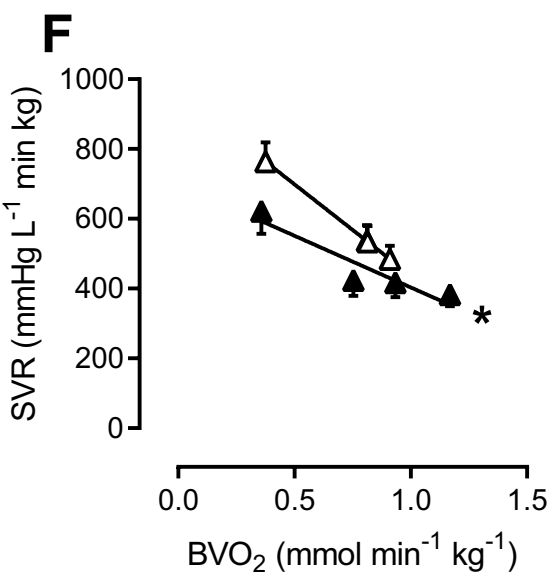

Fig. 8 Phosphodiesterase 5 (PDE5) in pulmonary and systemic vasomotor control in $\mathrm{DM}+\mathrm{HC}+\mathrm{CKD}$ and Healthy swine. The relation between transpulmonary gradient (TPG) and cardiac index shifted downward as a result of PDE5 inhibition (PDE5i) in $\mathrm{DM}+\mathrm{HC}+\mathrm{CKD}(\mathbf{C})$ but not in Healthy (A). PDE5i resulted in pulmonary vasodilation in $\mathrm{DM}+\mathrm{HC}+\mathrm{CKD}$ (D) but not in Healthy

VASP ratio in lung tissue was unchanged, which reflects similar PKG activity (Fig. 5). Furthermore, circulating nitrite + nitrate levels were similar in both groups (Table 3 ), although this is a rather insensitive measure that may not reflect the changes in NO bioavailability at the level of the lung vasculature. Similarly, iNOS mRNA, which has been shown to reflect iNOS protein [62], was not increased, and its expression was approximately threefold lower than expression of eNOS mRNA.

Further downstream in the NO-pathway, PDE5i resulted in a pulmonary vasodilation in $\mathrm{DM}+\mathrm{HC}+\mathrm{CKD}$ and normalized PVR, whereas no effect of PDE5i was observed in Healthy swine. The absence of a pulmonary vasodilator effect of PDE5i in Healthy swine is different from previous observations in which we showed a modest pulmonary vasodilator effect of PDE5 inhibition in Healthy swine [56, 58]. This difference is not readily explained, but may be the result of an age difference, as swine in the previous swine (B) as evidenced by the decrease in pulmonary vascular resistance (PVR). The reduction in systemic vascular resistance (SVR) with administration of PDE5i was similar between both groups. Healthy $n=6, \mathrm{DM}+\mathrm{HC}+\mathrm{CKD} n=7$. Values are mean \pm SEM. $* P \leq 0.05,{ }^{*} P \leq 0.1$ for effect PDE5i within group, $\left(^{\dagger}\right) P \leq 0.1$ for interaction PDE5i*group

studies were younger than in the present study. Similar to the present study, an increased response to PDE5i has been demonstrated in different swine models of type $2 \mathrm{PH}$, either due to pulmonary vein stenosis [58] or myocardial infarction [56]. In the present study, we observed no difference in PDE5 mRNA expression, but did not measure PDE5 protein or activity. Increased PDE5 protein expression and activity in the lung vasculature have been observed in experimentally-induced PH in lambs [5]. PDE5 mRNA and protein expression as well as activity in pulmonary vascular smooth muscle cells can be increased by oxidative stress $[16,40]$. mRNA expression of the anti-oxidant enzymes catalase and glutathione peroxidase was increased in $\mathrm{DM}+\mathrm{HC}+\mathrm{CKD}$, but SOD1 was decreased, whereas ROS scavenging with MPG and TEMPOL had no vasoactive effect in the pulmonary vasculature of either Healthy or DM $+\mathrm{HC}+\mathrm{CKD}$ swine. Nevertheless, upregulation of these anti-oxidant systems may have exerted a protective effect on the pulmonary 
A

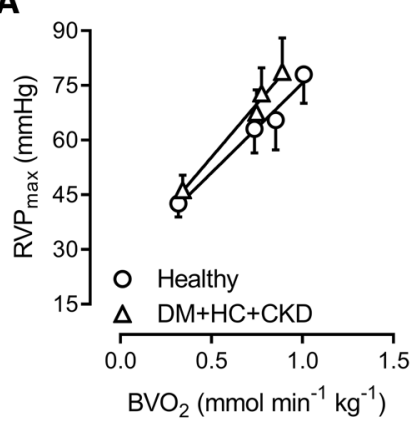

E

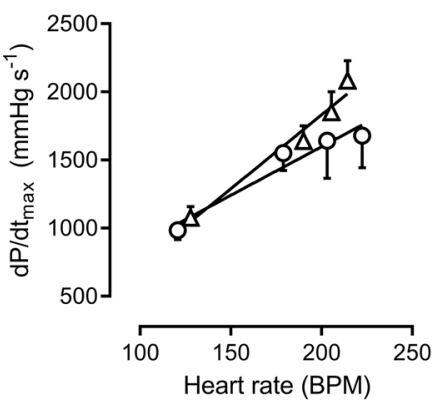

B

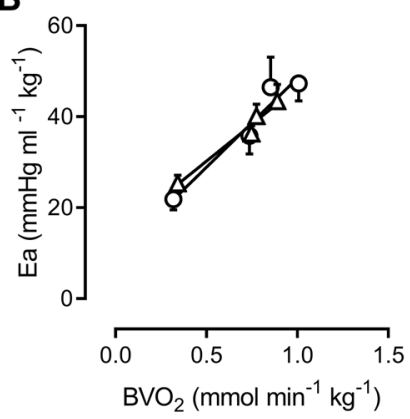

$\mathbf{F}$

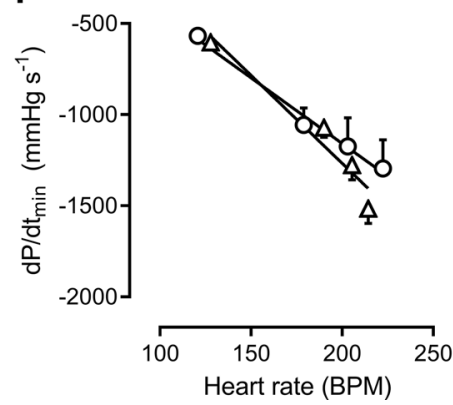

C

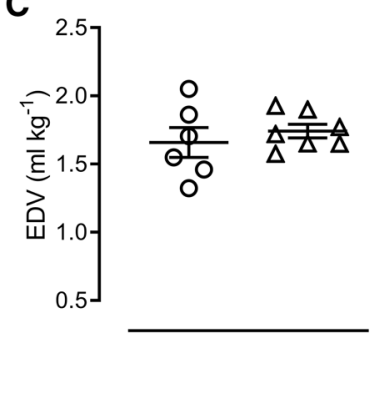

G

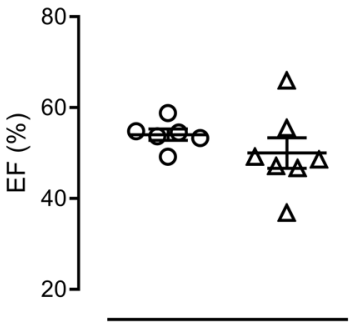

D

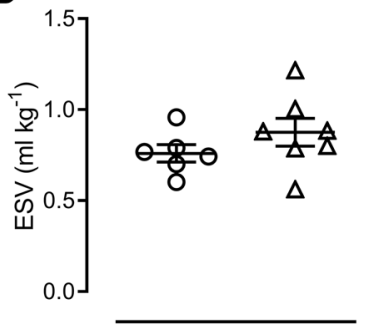

H

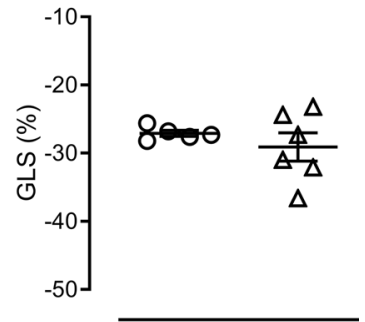

Fig. 9 Right ventricular function at rest, during exercise and during cardiovascular magnetic resonance imaging in $\mathrm{DM}+\mathrm{HC}+\mathrm{CKD}$ and Healthy swine. Right ventricular afterload at rest and during exercise was similar as the maximal right ventricular pressure $\left(\mathrm{RVP}_{\max }\right.$, A) and pulmonary arterial elastance $(\mathrm{Ea}, \mathbf{B})$ were similar between groups for any given level of body oxygen consumption $\left(\mathrm{BVO}_{2}\right)$. Systolic $\left(\mathrm{d} P / \mathrm{d} t_{\max }\right.$; maximum of the first derivate of the systolic RV pressure increase, E) and diastolic function $\left(\mathrm{d} P / \mathrm{d} t_{\min } ;\right.$ minimum of first

vasculature, as pulmonary perivascular inflammation tended to be reduced despite higher circulating TNF- $\alpha$ levels and MPG + TEMPOL did exert a vasodilator effect on the systemic vasculature of $\mathrm{DM}+\mathrm{HC}+\mathrm{CKD}$ only. It is known, however, that mRNA levels may not always adequately reflect protein levels. Hence, future studies should confirm these data at the protein level and determine the specific location of the upregulated anti-oxidant enzymes as well as changes in specific oxygen radicals that may have contributed to the increased PDE5 activity.

Conflicting results have been published with respect to the efficacy of PDE5 inhibition in HFpEF-PH, and recent meta-analyses concluded that there was no beneficial effect of PDE5 inhibition on pulmonary hemodynamics or exercise capacity $[4,8]$, although some individual studies did show a beneficial effect. It should be noted, however, that there were substantial differences in patient populations between studies and that the studies with negative results appeared to have higher proportions of post-capillary $\mathrm{PH}$ $[24,26,44]$. Conversely, one study that included patients with a higher PVR, resembling the pre-capillary arterial phenotype observed in this model, showed a beneficial effect of PDE5i [23]. These human data suggest that derivate of the RV diastolic pressure decrease, F) were preserved in $\mathrm{DM}+\mathrm{HC}+\mathrm{CKD}$ swine for any level of heart rate. $n=11$ for Healthy and $n=10$ for $\mathrm{DM}+\mathrm{HC}+\mathrm{CKD}$. Right ventricle cardiovascular magnetic resonance imaging parameters were measured under general anesthesia. End-diastolic (EDV, C) and end-systolic volume (ESV, D) ejection fraction (EF, G) and global longitudinal strain (GLS, H) were unaltered in $\mathrm{DM}+\mathrm{HC}+\mathrm{CKD}(n=7)$ compared to Healthy swine $(n=6)$. Values are mean \pm SEM

stratifying patients based on underlying disease may prove useful to identify subgroups of HFpEF-PH patients that may benefit from treatment. Stratification according to the presence of CKD may be necessary as PDE5 inhibition has been shown to either ameliorate [1], or worsen [42] kidney function and may thereby indirectly impact PVD.

Consistent with the increased ET-dependent vasoconstrictor influence on the pulmonary vasculature, circulating ET-1 levels were higher in swine with $\mathrm{DM}+\mathrm{HC}+\mathrm{CKD}$ as compared to Healthy controls suggesting either increased production or impaired clearance. The elevated ET-levels in our swine model are in accordance with human studies, showing elevated plasma ET-levels in HFpEF-PH patients correlating with PA pressures [7, 36, 41, 53], as well as with studies from our laboratory showing that plasma ET-levels are elevated in type II PH in swine, secondary to myocardial infarction [25] or due to pulmonary vein stenosis [58]. Furthermore, wedge ET-1 levels were shown to be higher than pulmonary arterial ET-levels and correlated with PVR in patients with combined pre-and post-capillary but not isolated post-capillary HFpEF-PH $[7,36]$, suggesting that the higher ET-1 levels in patients 


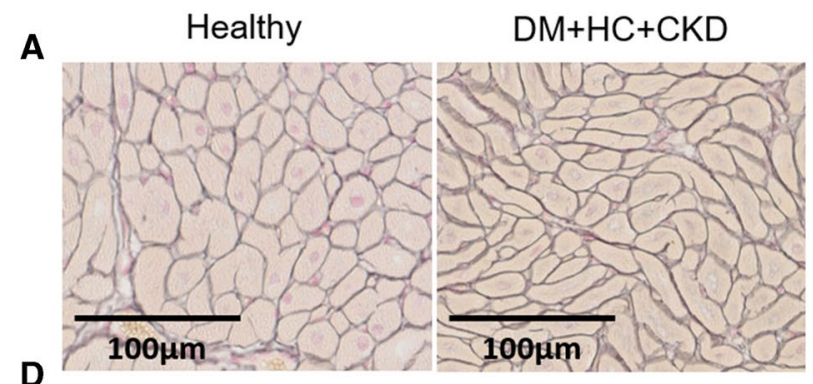

D
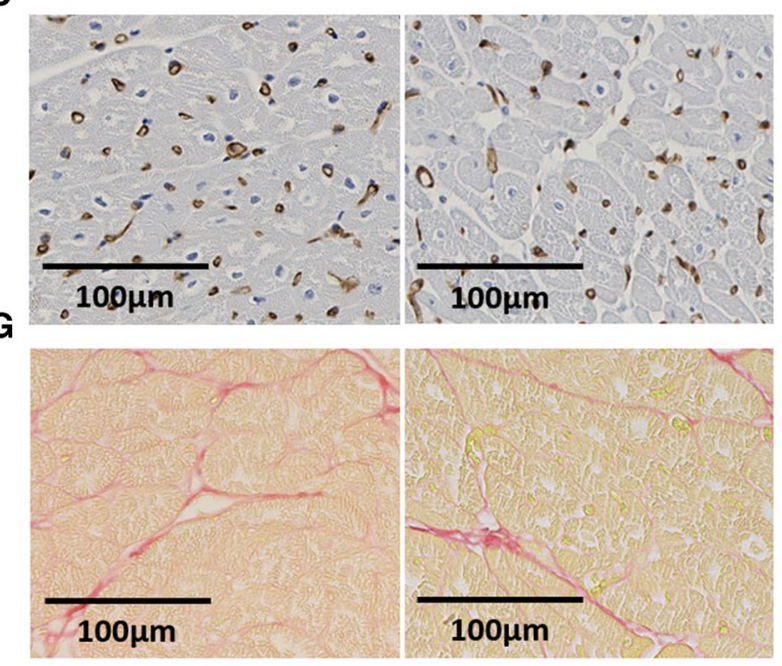
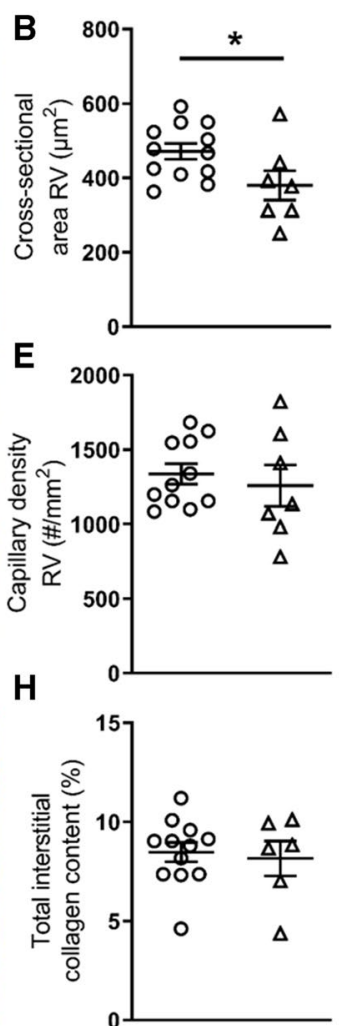
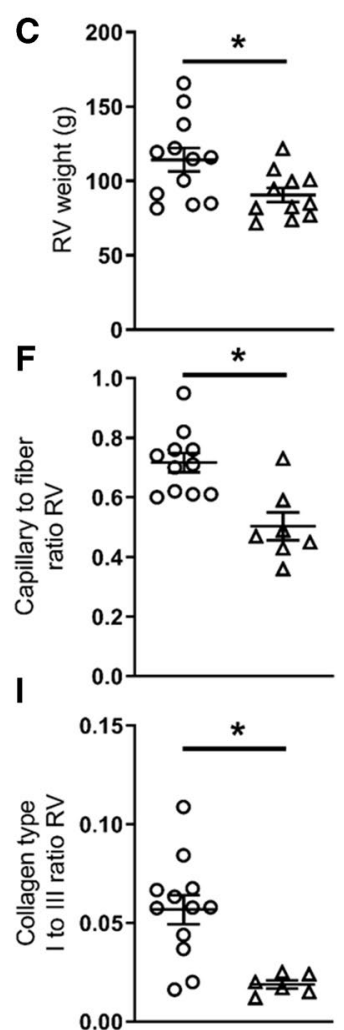

Fig. 10 Right ventricular structure of $\mathrm{DM}+\mathrm{HC}+\mathrm{CKD}$ and Healthy swine typical examples of right ventricular Gomori stained (A), Lectin stained (D) and Picrosirius red stained (G) sections. The cross-sectional area of the RV cardiomyocytes was decreased in $\mathrm{DM}+\mathrm{HC}+\mathrm{CKD}$ swine $(\mathbf{B}), \mathrm{RV}$ weight was also lower in $\mathrm{DM}+\mathrm{HC}+\mathrm{CKD}$ swine $(\mathbf{C})$. Capillary density was simi-

with combined pre- and post-capillary PH originate more distally in the pulmonary vasculature.

$\mathrm{ET}_{\mathrm{A}}$ and $\mathrm{ET}_{\mathrm{B}}$ receptors are expressed in the pulmonary circulation under both physiological and pathophysiological circumstances [15]. $\mathrm{ET}_{\mathrm{A}}$ is only present on vascular smooth muscle cells, mediating vasoconstriction, whereas $\mathrm{ET}_{\mathrm{B}}$ is present on both the vascular smooth muscle cell and the endothelial cells, mediating vasoconstriction and vasodilation, respectively. The lack of effect of $\mathrm{ET}_{\mathrm{A}+\mathrm{B}} \mathrm{i}$ in Healthy swine may be due to a balance between $\mathrm{ET}_{\mathrm{A}}$ and/ or $\mathrm{ET}_{\mathrm{B}}$-mediated vasoconstriction and $\mathrm{ET}_{\mathrm{B}}$-mediated vasodilation [39]. Although we previously showed that young, healthy swine do show a pulmonary vasodilator response to $\mathrm{ET}_{\mathrm{A}+\mathrm{B}} \mathrm{i}[25,37,38]$, this vasodilator response decreased with age [57]. The reason underlying this change is unclear, but may be due to altered $\mathrm{ET}_{\mathrm{A}}$ and/or $\mathrm{ET}_{\mathrm{B}}$ receptor expression or function with age. Similarly, in pathophysiological circumstances, $\mathrm{ET}_{\mathrm{A}}$ and $\mathrm{ET}_{\mathrm{B}}$ protein expression may be altered and the interaction with the NO-cGMP pathway may be altered $[39,63]$. In line with previous observations in swine with type II PH secondary to myocardial infarction lar between groups (E) but capillary-to-fiber ratio was lower in $\mathrm{DM}+\mathrm{HC}+\mathrm{CKD}(\mathbf{F})$. Total interstitial collagen content $(\mathbf{H})$ was unaltered in $\mathrm{DM}+\mathrm{HC}+\mathrm{CKD}$ swine, but there was a shift the composition of the specific collagen fibers in $\mathrm{DM}+\mathrm{HC}+\mathrm{CKD}(\mathbf{I})$. Values are mean \pm SEM. $* P \leq 0.05$ for Healthy versus $\mathrm{DM}+\mathrm{HC}+\mathrm{CKD}$, scale bars are $100 \mu \mathrm{m}$

[25] and pulmonary vein stenosis [57], $\mathrm{ET}_{\mathrm{A}+\mathrm{B}} \mathrm{i}$ produced a greater reduction in PVR in swine with $\mathrm{DM}+\mathrm{HC}+\mathrm{CKD}$, suggesting that the balance between the vasoconstrictor and vasodilator pathways is shifted towards vasoconstriction in the $\mathrm{DM}+\mathrm{HC}+\mathrm{CKD}$ swine, and consistent with a withdrawal of endothelial $\mathrm{ET}_{\mathrm{B}}$ influence. Indeed, immunohistochemical analysis showed reduced $\mathrm{ET}_{\mathrm{B}}$ receptor staining on the pulmonary endothelium in $\mathrm{DM}+\mathrm{HC}+\mathrm{CKD}$ swine. Immunohistochemical staining of $\mathrm{ET}_{\mathrm{A}}$ receptors failed due to lack of a porcine specific antibody suitable for immunohistochemistry. Furthermore, given the partial muscularization of the pulmonary arterioles, with few smooth muscle cells surrounding the lumen, it was not possible to reliably measure $\mathrm{ET}_{\mathrm{B}}$ receptor staining of the medial layer. Nevertheless, loss of endothelial $\mathrm{ET}_{\mathrm{B}}$ receptors may result in reduced ET-1 clearance [13, 14], thereby explaining the increased circulating levels of ET-1 found swine with $\mathrm{DM}+\mathrm{HC}+\mathrm{CKD}$ in our study.

The balance between the ET and NO pathways in the pulmonary vasculature under physiological circumstances is nicely illustrated by the data in Healthy swine, where 


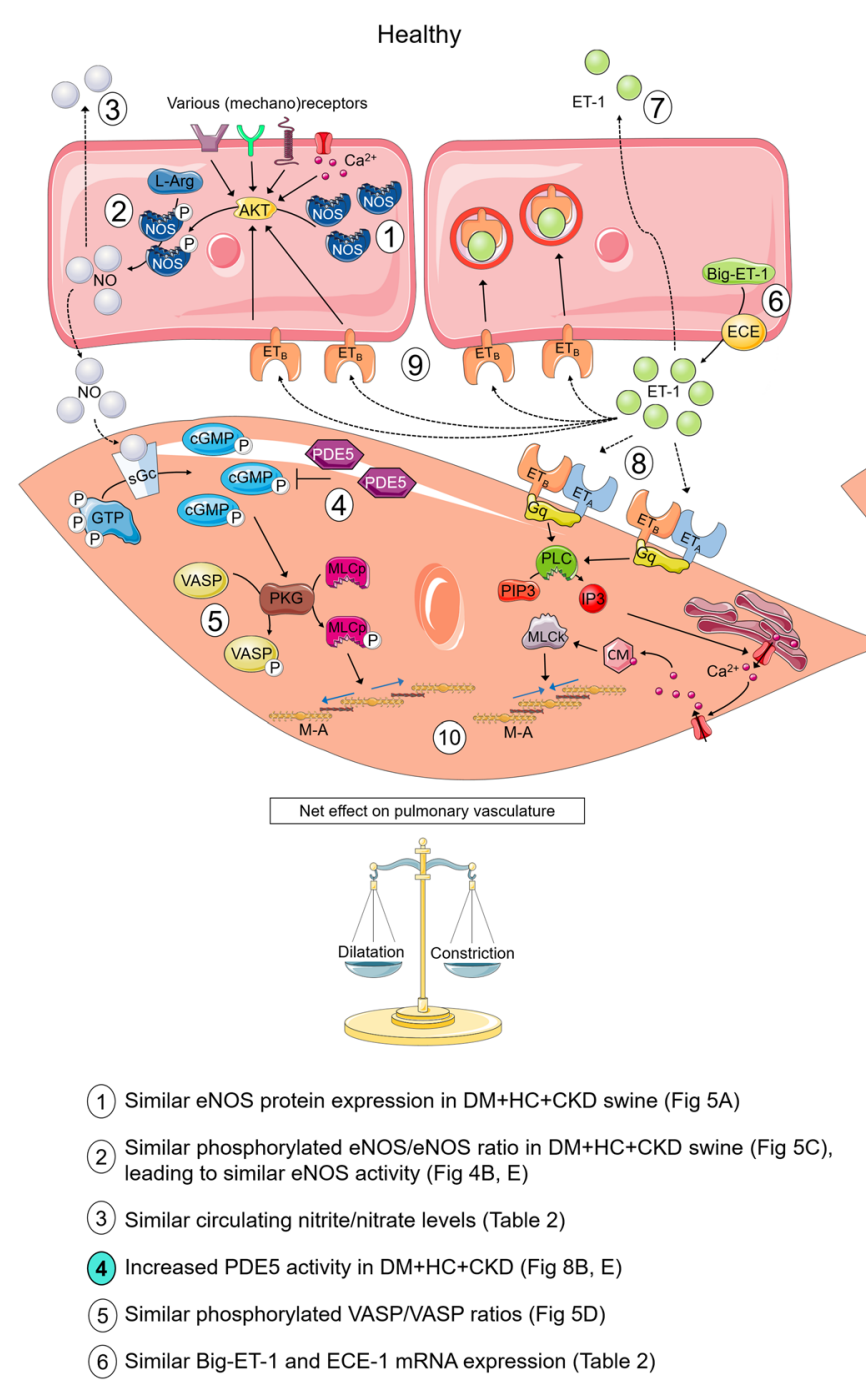

Fig. 11 Proposed mechanisms of pulmonary vascular dysfunction in $\mathrm{DM}+\mathrm{HC}+\mathrm{CKD}$. Upper cells represent endothelial cells, lower cells the smooth muscle cells. Significant differences in DM+HC + CKD compared to Healthy are shown as highlighted numbers in the figure. $A K T$ protein kinase $\mathrm{B}, B i g-E T-1$ big endothelin $1, \mathrm{Ca}^{2+}$ calcium, cGMP cyclic guanosine monophosphate, $C M$ calmodulin, $E C E$ endothelin converting enzyme, ET-1 endothelin 1,ET endothelin receptor A, $E T_{B}$ endothelin receptor $\mathrm{B}, G T P$ guanosine triphosphate, $G q \mathrm{G}$ alpha subunit, IP3 inositol triphosphate, L-Arg L-arginine,

NOSi unmasked a vasodilator effect of subsequent $\mathrm{ET}_{\mathrm{A}+\mathrm{B}} \mathrm{i}$. These data suggest that in Healthy swine, the vasoconstrictor effect of ET, mediated through activation of the $\mathrm{ET}_{\mathrm{A}}$ and/or $\mathrm{ET}_{\mathrm{B}}$ receptors on vascular smooth muscle cells is balanced by a vasodilator influence, through the endothelial $\mathrm{ET}_{\mathrm{B}}$ receptor with subsequent activation of the NOcGMP pathway. NOSi abrogates this vasodilator action of $\mathrm{ET}_{\mathrm{B}}$-activation, thereby unmasking a vasoconstrictor effect of ET in the Healthy pulmonary vasculature. Conversely, in swine with $\mathrm{DM}+\mathrm{HC}+\mathrm{CKD}$, the effect of $\mathrm{ET}_{\mathrm{A}+\mathrm{B}} \mathrm{i}$ was similar in the presence and absence of NOSi, consistent
$\mathrm{DM}+\mathrm{HC}+\mathrm{CKD}$

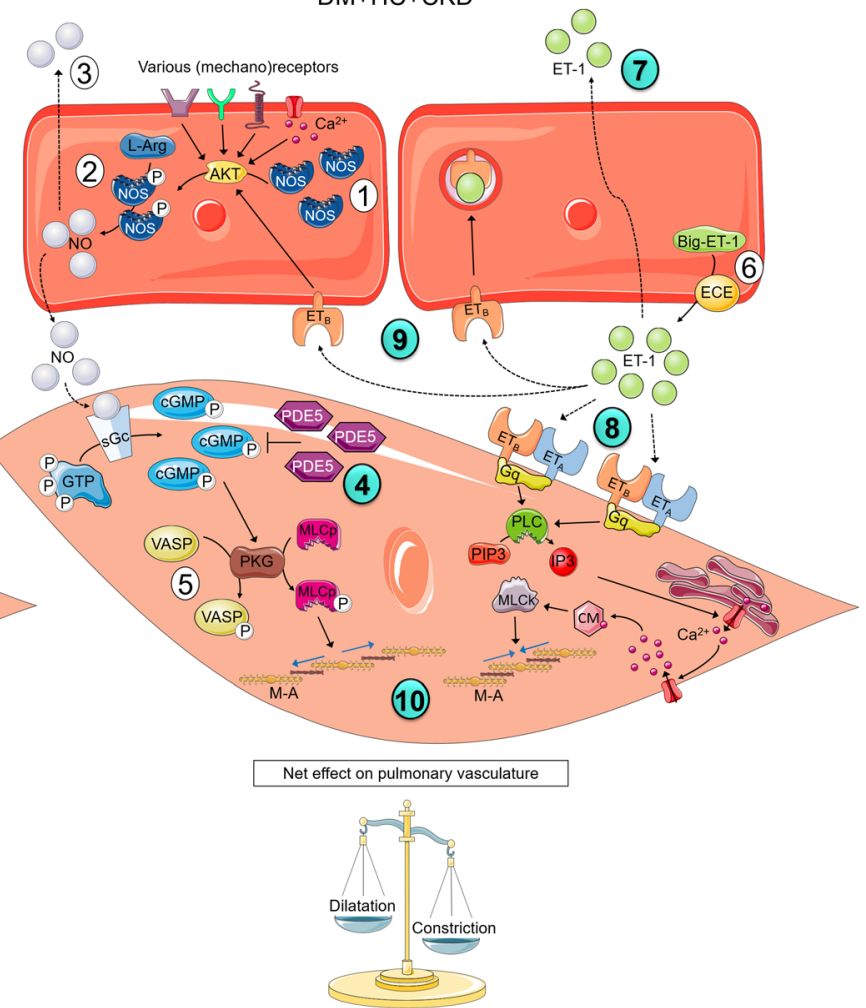

7) Increased circulating ET-1 levels in DM+HC+CKD (Table 2)

(8) Increased vasoconstrictor effect of $\mathrm{ET}_{\mathrm{A}+\mathrm{B}}$ activity in $\mathrm{DM}+\mathrm{HC}+\mathrm{CKD}$ (Fig 3B, E) Decreased endothelial $\mathrm{ET}_{\mathrm{B}}$ abundance (Fig 2F) and activity (Fig 7B, E) in 9) $\mathrm{DM}+\mathrm{HC}+\mathrm{CKD}$

Imbalance in the vasodilator activity of endothelial $\mathrm{ET}_{\mathrm{B}}$ and vasoconstrictor activity (10) of $S M C E T_{A+B}$, in combination with increased PDE5 activity leads to increased pulmonary vascular resistance in $\mathrm{DM}+\mathrm{HC}+\mathrm{CKD}$ swine $($ Fig $1 \mathrm{H})$

$M-A$ myosin-actin, $M L C k$ myosin light chain kinase, $M L C p$ myosin light chain phosphatase, $N O$ nitric oxide, $N O S$ nitric oxide synthase, $P D E 5$ phosphodiesterase 5, PIP3 phosphatidylinositol triphosphate, $P K G$ protein kinase $\mathrm{G}, P L C$ phospholipase $\mathrm{C}, s G c$ soluble guanylate cyclase, $S M C$ smooth muscle cell, VASP vasodilatation stimulating proteins. This figure is produced by adapting images from Servier Medical Art by Servier (https://smart.servier.com/), licensed under a Creative Commons attribution 3.0 Unported Licence

with a loss of endothelial $\mathrm{ET}_{\mathrm{B}}$ receptors, which was confirmed histologically. Our data imply that an imbalance in the contribution of $\mathrm{ET}_{\mathrm{A}}$ and $\mathrm{ET}_{\mathrm{B}}$ to pulmonary vasomotor control-specifically loss of $\mathrm{ET}_{\mathrm{B}}$-mediated vasodilation-plays an important role in the increase in PVR in our model (Fig. 11). Such protective role of the endothelial $\mathrm{ET}_{\mathrm{B}}$ receptor against development of $\mathrm{PH}$ was also observed in a study in mice with endothelial-specific $\mathrm{ET}_{\mathrm{B}}$ knockout, which showed aggravated hypoxia-induced $\mathrm{PH}$ [28]. Similarly, loss of endothelial $\mathrm{ET}_{\mathrm{B}}$ receptors in $\mathrm{PH}$ was observed in a rat model of monocrotaline-induced 
$\mathrm{PH}$, in which stimulation of $\mathrm{ET}_{\mathrm{B}}$ resulted in pulmonary endothelium-dependent pulmonary vasodilation in healthy rats, which was converted into vasoconstriction in rats with PH [27].

Our study suggests that ET-receptor antagonism may be beneficial particularly in early pulmonary vascular disease secondary to multiple comorbidities. Yet, no beneficial effects of 12 weeks of $\mathrm{ET}_{\mathrm{A}+\mathrm{B}} \mathrm{i}$ with either bosentan or macitentan were observed in patients with HFpEF-PH in the BADDHY [30] and the MELODY-1 [53] studies, respectively, whereas fluid retention did occur as a side-effect of chronic $\mathrm{ET}_{\mathrm{A}+\mathrm{B}} \mathrm{i}$ in a subgroup of patients in the MELODY-1 trial. However, our model represents early stage disease. Furthermore, as ET-1 levels rise when kidney function declines and endothelin-antagonism may also be reno-protective [29], careful patient selection and/or combination with a diuretic may reveal a subgroup of early HFpEF patients with CKD in which endothelin-antagonism is protective against progression of PVD. Alternatively, other ways of interfering with the NO-ET balance may be beneficial in HFpEF-PH. Relaxin-2, which is a hormone with an insulin-like structure, has been shown to cause NO-mediated vasodilation and interfere with ET-induced vasoconstriction, by upregulating endothelial $\mathrm{ET}_{\mathrm{B}}$ expression. It also ameliorates endothelial as well as metabolic dysfunction in diabetes, making it a promising therapeutic compound for both HFpEF as well as HFpEF-PH [12, 17]. Future studies should test this interesting compound in our swine model with comorbiditiesinduced PVD.

\section{Conclusion}

The present study is the first to investigate the effects of three common comorbidities on pulmonary vasomotor control and $\mathrm{RV}$ function and structure in swine at rest and during graded treadmill exercise. Our findings demonstrate that, in the absence of overt PH, comorbidities result in increased PVR due to alterations in pulmonary vascular vasomotor control. At this early stage of PVD, neither pronounced pulmonary structural changes nor RV functional and structural changes are present. These findings support the concept that changes in pulmonary vascular vasomotor control are present early in the development of PVD in patients with comorbidities, and suggest that restoring the pulmonary vasomotor balance before overt $\mathrm{PH}$ occurs might prove a valuable therapeutic target in patients with early HFpEF and PVD.

Supplementary Information The online version contains supplementary material available at https://doi.org/10.1007/s00395-021-00891-7.

Acknowledgements The authors thank Annemarie Verzijl, Esther van der Kamp, Ilona Krabbendam, Lau Blonden, Richard van Duin,
Marjoke Koster and Fanny Leandre (Erasmus MC, Rotterdam, The Netherlands) for their expert technical support.

Author contributions JW, OS, DM and DJD conceptualized and designed the experiments. JW, JS, OS, RD, AK, PW, AH and DM performed the experiments, JW, JS and DM drafted the initial manuscript, all authors have read and revised the final manuscript and approved it for publication.

Funding This study was supported by grants from the European Commission FP7-Health-2010 Grant MEDIA-261409, the German Center for Cardiovascular Research (DZHK; $81 Z 0600207$ to DM), The Netherlands CardioVascular Research Initiative: an initiative with support of the Dutch Heart Foundation [CVON2012-08 (PHAEDRA), CVON2014-11 (RECONNECT)] and the Erasmus MC.

\section{Declarations}

Conflict of interest Not applicable.

Open Access This article is licensed under a Creative Commons Attribution 4.0 International License, which permits use, sharing, adaptation, distribution and reproduction in any medium or format, as long as you give appropriate credit to the original author(s) and the source, provide a link to the Creative Commons licence, and indicate if changes were made. The images or other third party material in this article are included in the article's Creative Commons licence, unless indicated otherwise in a credit line to the material. If material is not included in the article's Creative Commons licence and your intended use is not permitted by statutory regulation or exceeds the permitted use, you will need to obtain permission directly from the copyright holder. To view a copy of this licence, visit http://creativecommons.org/licenses/by/4.0/.

\section{References}

1. Afsar B, Ortiz A, Covic A, Gaipov A, Esen T, Goldsmith D, Kanbay M (2015) Phosphodiesterase type 5 inhibitors and kidney disease. Int Urol Nephrol 47:1521-1528. https://doi.org/10.1007/ s11255-015-1071-4

2. Andreadou I, Schulz R, Badimon L, Adameova A, Kleinbongard P, Lecour S, Nikolaou PE, Falcao-Pires I, Vilahur G, Woudberg N, Heusch G, Ferdinandy P (2019) Hyperlipidaemia and cardioprotection: Animal models for translational studies. Br J Pharmacol. https://doi.org/10.1111/bph.14931

3. Assad TR, Maron BA, Robbins IM, Xu M, Huang S, Harrell FE, Farber-Eger EH, Wells QS, Choudhary G, Hemnes AR, Brittain EL (2017) Prognostic effect and longitudinal hemodynamic assessment of borderline pulmonary hypertension. JAMA Cardiol 2:1361-1368. https://doi.org/10.1001/jamacardio.2017.3882

4. Barnes H, Brown Z, Burns A, Williams T (2019) Phosphodiesterase 5 inhibitors for pulmonary hypertension. Cochrane Database Syst Rev. https://doi.org/10.1002/14651858.CD012621.pub2

5. Black SM, Sanchez LS, Mata-Greenwood E, Bekker JM, Steinhorn RH, Fineman JR (2001) sGC and PDE5 are elevated in lambs with increased pulmonary blood flow and pulmonary hypertension. Am J Physiol Lung Cell Mol Physiol 281:L1051-1057. https://doi.org/10.1152/ajplung.2001.281.5.L1051

6. Caughey MC, Detwiler RK, Sivak JA, Rose-Jones LJ, Kshirsagar AV, Hinderliter AL (2019) Five-year outcomes of pulmonary hypertension with and without elevated left atrial pressure in patients evaluated for kidney transplantation. Transplantation. https://doi.org/10.1097/TP.0000000000003068 
7. Chowdhury MA, Moukarbel GV, Gupta R, Frank SM, Anderson AM, Liu LC, Khouri SJ (2019) Endothelin 1 is associated with heart failure hospitalization and long-term mortality in patients with heart failure with preserved ejection fraction and pulmonary hypertension. Cardiology 143:124-133. https://doi.org/10.1159/ 000501100

8. De Vecchis R, Cesaro A, Ariano C, Giasi A, Cioppa C (2017) Phosphodiesterase-5 inhibitors improve clinical outcomes, exercise capacity and pulmonary hemodynamics in patients with heart failure with reduced left ventricular ejection fraction: a meta-analysis. J Clin Med Res 9:488-498. https://doi.org/10.14740/jocmr $3008 \mathrm{w}$

9. De Wijs-Meijler DP, Stam K, van Duin RW, Verzijl A, Reiss IK, Duncker DJ, Merkus D (2016) Surgical placement of catheters for long-term cardiovascular exercise testing in swine. J Vis Exp. https://doi.org/10.3791/53772

10. Dhingra A, Garg A, Kaur S, Chopra S, Batra JS, Pandey A, Chaanine AH, Agarwal SK (2014) Epidemiology of heart failure with preserved ejection fraction. Curr Heart Fail Rep 11:354-365. https://doi.org/10.1007/s11897-014-0223-7

11. Douschan P, Kovacs G, Avian A, Foris V, Gruber F, Olschewski A, Olschewski H (2018) Mild elevation of pulmonary arterial pressure as a predictor of mortality. Am J Respir Crit Care Med 197:509-516. https://doi.org/10.1164/rccm.201706-1215OC

12. Dschietzig TB (2019) Relaxin-2 for heart failure with preserved ejection fraction (HFpEF): rationale for future clinical trials. Mol Cell Endocrinol 487:54-58. https://doi.org/10.1016/j.mce.2019. 01.013

13. Dupuis J, Cernacek P, Tardif JC, Stewart DJ, Gosselin G, Dyrda I, Bonan R, Crepeau J (1998) Reduced pulmonary clearance of endothelin-1 in pulmonary hypertension. Am Heart J 135:614620. https://doi.org/10.1016/s0002-8703(98)70276-5

14. Dupuis J, Goresky CA, Fournier A (1996) Pulmonary clearance of circulating endothelin-1 in dogs in vivo: exclusive role of ETB receptors. J Appl Physiol (1985) 81:1510-1515. https://doi.org/ 10.1152/jappl.1996.81.4.1510

15. Fagan KA, McMurtry IF, Rodman DM (2001) Role of endothelin-1 in lung disease. Respir Res 2:90-101. https://doi.org/10. $1186 / \mathrm{rr} 44$

16. Farrow KN, Groh BS, Schumacker PT, Lakshminrusimha S, Czech L, Gugino SF, Russell JA, Steinhorn RH (2008) Hyperoxia increases phosphodiesterase 5 expression and activity in ovine fetal pulmonary artery smooth muscle cells. Circ Res 102:226233. https://doi.org/10.1161/CIRCRESAHA.107.161463

17. Feijoo-Bandin S, Aragon-Herrera A, Rodriguez-Penas D, Portoles M, Rosello-Lleti E, Rivera M, Gonzalez-Juanatey JR, Lago F (2017) Relaxin-2 in cardiometabolic diseases: mechanisms of action and future perspectives. Front Physiol 8:599. https://doi. org/10.3389/fphys.2017.00599

18. Flamm SD, Taki J, Moore R, Lewis SF, Keech F, Maltais F, Ahmad M, Callahan R, Dragotakes S, Alpert N et al (1990) Redistribution of regional and organ blood volume and effect on cardiac function in relation to upright exercise intensity in healthy human subjects. Circulation 81:1550-1559

19. Franssen C, Chen S, Unger A, Korkmaz HI, De Keulenaer GW, Tschope C, Leite-Moreira AF, Musters R, Niessen HW, Linke WA, Paulus WJ, Hamdani N (2016) Myocardial microvascular inflammatory endothelial activation in heart failure with preserved ejection fraction. JACC Heart Fail 4:312-324. https://doi.org/10. 1016/j.jchf.2015.10.007

20. Gohar EY, Giachini FR, Pollock DM, Tostes RC (2016) Role of the endothelin system in sexual dimorphism in cardiovascular and renal diseases. Life Sci 159:20-29. https://doi.org/10.1016/j.lfs. 2016.02.093

21. Gorter TM, Obokata M, Reddy YNV, Melenovsky V, Borlaug BA (2018) Exercise unmasks distinct pathophysiologic features in heart failure with preserved ejection fraction and pulmonary vascular disease. Eur Heart J 39:2825-2835. https://doi.org/10. 1093/eurheartj/ehy331

22. Gorter TM, van Veldhuisen DJ, Bauersachs J, Borlaug BA, Celutkiene J, Coats AJS, Crespo-Leiro MG, Guazzi M, Harjola VP, Heymans S, Hill L, Lainscak M, Lam CSP, Lund LH, Lyon AR, Mebazaa A, Mueller C, Paulus WJ, Pieske B, Piepoli MF, Ruschitzka F, Rutten FH, Seferovic PM, Solomon SD, Shah SJ, Triposkiadis F, Wachter R, Tschope C, de Boer RA (2018) Right heart dysfunction and failure in heart failure with preserved ejection fraction: mechanisms and management. Position statement on behalf of the Heart Failure Association of the European Society of Cardiology. Eur J Heart Fail 20:16-37. https://doi.org/10.1002/ ejhf.1029

23. Guazzi M, Vicenzi M, Arena R, Guazzi MD (2011) Pulmonary hypertension in heart failure with preserved ejection fraction: a target of phosphodiesterase-5 inhibition in a 1-year study. Circulation 124:164-174. https://doi.org/10.1161/CIRCULATIONAHA. 110.983866

24. Hoendermis ES, Liu LC, Hummel YM, van der Meer P, de Boer RA, Berger RM, van Veldhuisen DJ, Voors AA (2015) Effects of sildenafil on invasive haemodynamics and exercise capacity in heart failure patients with preserved ejection fraction and pulmonary hypertension: a randomized controlled trial. Eur Heart J 36:2565-2573. https://doi.org/10.1093/eurheartj/ehv336

25. Houweling B, Merkus D, Sorop O, Boomsma F, Duncker DJ (2006) Role of endothelin receptor activation in secondary pulmonary hypertension in awake swine after myocardial infarction. J Physiol 574:615-626. https://doi.org/10.1113/jphysiol.2006. 107060

26. Hussain I, Mohammed SF, Forfia PR, Lewis GD, Borlaug BA, Gallup DS, Redfield MM (2016) Impaired right ventricular-pulmonary arterial coupling and effect of sildenafil in heart failure with preserved ejection fraction: an ancillary analysis from the phosphodiesterase-5 inhibition to improve clinical status and exercise capacity in diastolic heart failure (RELAX) trial. Circ Heart Fail 9:e002729. https://doi.org/10.1161/CIRCHEARTFAILURE. 115.002729

27. Iglarz M, Steiner P, Wanner D, Rey M, Hess P, Clozel M (2015) Vascular effects of endothelin receptor antagonists depends on their selectivity for ETA versus ETB receptors and on the functionality of endothelial ETB receptors. J Cardiovasc Pharmacol 66:332-337. https://doi.org/10.1097/FJC.0000000000000283

28. Kelland NF, Bagnall AJ, Morecroft I, Gulliver-Sloan FH, Dempsie Y, Nilsen M, Yanagisawa M, Maclean MR, Kotelevtsev YV, Webb DJ (2010) Endothelial ET(B) limits vascular remodelling and development of pulmonary hypertension during hypoxia. $\mathbf{J}$ Vasc Res 47:16-22. https://doi.org/10.1159/000231717

29. Kohan DE, Barton M (2014) Endothelin and endothelin antagonists in chronic kidney disease. Kidney Int 86:896-904. https:// doi.org/10.1038/ki.2014.143

30. Koller B, Steringer-Mascherbauer R, Ebner CH, Weber T, Ammer M, Eichinger J, Pretsch I, Herold M, Schwaiger J, Ulmer H, Grander W (2017) Pilot study of endothelin receptor blockade in heart failure with diastolic dysfunction and pulmonary hypertension (BADDHY-Trial). Heart Lung Circ 26:433-441. https://doi. org/10.1016/j.hlc.2016.09.004

31. Lai YC, Wang L, Gladwin MT (2019) Insights into the pulmonary vascular complications of heart failure with preserved ejection fraction. J Physiol 597:1143-1156. https://doi.org/10.1113/JP275 858

32. Lam CS, Roger VL, Rodeheffer RJ, Borlaug BA, Enders FT, Redfield MM (2009) Pulmonary hypertension in heart failure with preserved ejection fraction: a community-based study. J Am Coll Cardiol 53:1119-1126. https://doi.org/10.1016/j.jacc.2008.11.051 
33. Levine AR, Simon MA, Gladwin MT (2018) Pulmonary vascular disease in the setting of heart failure with preserved ejection fraction. Trends Cardiovasc Med. https://doi.org/10.1016/j.tcm.2018. 08.005

34. Lewis GD, Bossone E, Naeije R, Grunig E, Saggar R, Lancellotti P, Ghio S, Varga J, Rajagopalan S, Oudiz R, Rubenfire M (2013) Pulmonary vascular hemodynamic response to exercise in cardiopulmonary diseases. Circulation 128:1470-1479. https://doi.org/ 10.1161/CIRCULATIONAHA.112.000667

35. Maron BA, Hess E, Maddox TM, Opotowsky AR, Tedford RJ, Lahm T, Joynt KE, Kass DJ, Stephens T, Stanislawski MA, Swenson ER, Goldstein RH, Leopold JA, Zamanian RT, Elwing JM, Plomondon ME, Grunwald GK, Baron AE, Rumsfeld JS, Choudhary G (2016) Association of borderline pulmonary hypertension with mortality and hospitalization in a large patient cohort: insights from the veterans affairs clinical assessment, reporting, and tracking program. Circulation 133:1240-1248. https://doi.org/ 10.1161/CIRCULATIONAHA.115.020207

36. Meoli DF, Su YR, Brittain EL, Robbins IM, Hemnes AR, Monahan K (2018) The transpulmonary ratio of endothelin 1 is elevated in patients with preserved left ventricular ejection fraction and combined pre- and post-capillary pulmonary hypertension. Pulm Circ 8:2045893217745019. https://doi.org/10.1177/2045893217 745019

37. Merkus D, Houweling B, de Beer VJ, Everon Z, Duncker DJ (2007) Alterations in endothelial control of the pulmonary circulation in exercising swine with secondary pulmonary hypertension after myocardial infarction. J Physiol 580:907-923. https://doi. org/10.1113/jphysiol.2006.127118

38. Merkus D, Houweling B, Mirza A, Boomsma F, van den Meiracker AH, Duncker DJ (2003) Contribution of endothelin and its receptors to the regulation of vascular tone during exercise is different in the systemic, coronary and pulmonary circulation. Cardiovasc Res 59:745-754. https://doi.org/10.1016/s00086363(03)00479-6

39. Moraes DL, Colucci WS, Givertz MM (2000) Secondary pulmonary hypertension in chronic heart failure: the role of the endothelium in pathophysiology and management. Circulation 102:1718-1723. https://doi.org/10.1161/01.cir.102.14.1718

40. Muzaffar S, Shukla N, Bond M, Sala-Newby GB, Newby AC, Angelini GD, Jeremy JY (2008) Superoxide from NADPH oxidase upregulates type 5 phosphodiesterase in human vascular smooth muscle cells: inhibition with iloprost and NONOate. Br J Pharmacol 155:847-856. https://doi.org/10.1038/bjp.2008.300

41. Obokata M, Kane GC, Reddy YNV, Melenovsky V, Olson TP, Jarolim P, Borlaug BA (2019) The neurohormonal basis of pulmonary hypertension in heart failure with preserved ejection fraction. Eur Heart J 40:3707-3717. https://doi.org/10.1093/eurheartj/ ehz626

42. Patel RB, Mehta R, Redfield MM, Borlaug BA, Hernandez AF, Shah SJ, Dubin RF (2020) Renal dysfunction in heart failure with preserved ejection fraction: insights from the RELAX trial. J Card Fail. https://doi.org/10.1016/j.cardfail.2020.01.003

43. Paulus WJ, Tschope $\mathrm{C}$ (2013) A novel paradigm for heart failure with preserved ejection fraction comorbidities drive myocardial dysfunction and remodeling through coronary microvascular endothelial inflammation. J Am Coll Cardiol 62:263-271. https:// doi.org/10.1016/J.Jacc.2013.02.092

44. Redfield MM, Chen HH, Borlaug BA, Semigran MJ, Lee KL, Lewis G, LeWinter MM, Rouleau JL, Bull DA, Mann DL, Deswal A, Stevenson LW, Givertz MM, Ofili EO, O'Connor CM, Felker GM, Goldsmith SR, Bart BA, McNulty SE, Ibarra JC, Lin G, Oh JK, Patel MR, Kim RJ, Tracy RP, Velazquez EJ, Anstrom KJ, Hernandez AF, Mascette AM, Braunwald E, Trial R (2013) Effect of phosphodiesterase-5 inhibition on exercise capacity and clinical status in heart failure with preserved ejection fraction: a randomized clinical trial. JAMA 309:1268-1277. https://doi.org/ 10.1001/jama.2013.2024

45. Regitz-Zagrosek V, Kararigas G (2017) Mechanistic pathways of sex differences in cardiovascular disease. Physiol Rev 97:1-37. https://doi.org/10.1152/physrev.00021.2015

46. Shah SJ, Borlaug BA, Kitzman DW, McCulloch AD, Blaxall BC, Agarwal R, Chirinos JA, Collins S, Deo RC, Gladwin MT, Granzier H, Hummel SL, Kass DA, Redfield MM, Sam F, Wang TJ, Desvigne-Nickens P, Adhikari BB (2020) Research priorities for heart failure with preserved ejection fraction: National Heart, Lung, and Blood Institute Working Group Summary. Circulation 141:1001-1026. https://doi.org/10.1161/CIRCULATIONAHA. 119.041886

47. Shah SJ, Katz DH, Selvaraj S, Burke MA, Yancy CW, Gheorghiade M, Bonow RO, Huang CC, Deo RC (2015) Phenomapping for novel classification of heart failure with preserved ejection fraction. Circulation 131:269-279. https://doi.org/10.1161/CIRCU LATIONAHA.114.010637

48. Shah SJ, Kitzman DW, Borlaug BA, van Heerebeek L, Zile MR, Kass DA, Paulus WJ (2016) Phenotype-specific treatment of heart failure with preserved ejection fraction: a multiorgan roadmap. Circulation 134:73-90. https://doi.org/10.1161/CIRCULATIO NAHA.116.021884

49. Simonneau G, Montani D, Celermajer DS, Denton CP, Gatzoulis MA, Krowka M, Williams PG, Souza R (2019) Haemodynamic definitions and updated clinical classification of pulmonary hypertension. Eur Respir J. https://doi.org/10.1183/13993003. 01913-2018

50. Sorop O, Heinonen I, van Kranenburg M, van de Wouw J, de Beer VJ, Nguyen ITN, Octavia Y, van Duin RWB, Stam K, van Geuns RJ, Wielopolski PA, Krestin GP, van den Meiracker AH, Verjans R, van Bilsen M, Danser AHJ, Paulus WJ, Cheng C, Linke WA, Joles JA, Verhaar MC, van der Velden J, Merkus D, Duncker DJ (2018) Multiple common comorbidities produce left ventricular diastolic dysfunction associated with coronary microvascular dysfunction, oxidative stress, and myocardial stiffening. Cardiovasc Res 114:954-964. https://doi.org/10.1093/cvr/cvy038

51. Tang M, Batty JA, Lin C, Fan X, Chan KE, Kalim S (2018) Pulmonary hypertension, mortality, and cardiovascular disease in CKD and ESRD patients: a systematic review and meta-analysis. Am J Kidney Dis 72:75-83. https://doi.org/10.1053/j.ajkd.2017. 11.018

52. Ter Maaten JM, Damman K, Verhaar MC, Paulus WJ, Duncker DJ, Cheng C, van Heerebeek L, Hillege HL, Lam CS, Navis G, Voors AA (2016) Connecting heart failure with preserved ejection fraction and renal dysfunction: the role of endothelial dysfunction and inflammation. Eur J Heart Fail 18:588-598. https://doi.org/ 10.1002/ejhf.497

53. Vachiery JL, Delcroix M, Al-Hiti H, Efficace M, Hutyra M, Lack G, Papadakis K, Rubin LJ (2018) Macitentan in pulmonary hypertension due to left ventricular dysfunction. Eur Respir J. https:// doi.org/10.1183/13993003.01886-2017

54. van de Wouw J, Broekhuizen M, Sorop O, Joles JA, Verhaar MC, Duncker DJ, Danser AHJ, Merkus D (2019) Chronic kidney disease as a risk factor for heart failure with preserved ejection fraction: a focus on microcirculatory factors and therapeutic targets. Front Physiol 10:1108. https://doi.org/10.3389/fphys.2019.01108

55. van de Wouw J, Sorop O, van Drie RWA, van Duin RWB, Nguyen ITN, Joles JA, Verhaar MC, Merkus D, Duncker DJ (2020) Perturbations in myocardial perfusion and oxygen balance in swine with multiple risk factors: a novel model of ischemia and no obstructive coronary artery disease. Basic Res Cardiol 115:21. https://doi.org/ 10.1007/s00395-020-0778-2

56. van Duin RWB, Houweling B, Uitterdijk A, Duncker DJ, Merkus D (2018) Pulmonary vasodilation by phosphodiesterase 5 inhibition is enhanced and nitric oxide independent in early pulmonary 
hypertension after myocardial infarction. Am J Physiol Heart Circ Physiol 314:H170-H179. https://doi.org/10.1152/ajpheart.00370. 2017

57. van Duin RWB, Stam K, Cai Z, Uitterdijk A, Garcia-Alvarez A, Ibanez B, Danser AHJ, Reiss IKM, Duncker DJ, Merkus D (2019) Transition from post-capillary pulmonary hypertension to combined pre- and post-capillary pulmonary hypertension in swine: a key role for endothelin. J Physiol 597:1157-1173. https://doi.org/ 10.1113/JP275987

58. van Duin RWB, Stam K, Uitterdijk A, Bartelds B, Danser AHJ, Reiss IKM, Duncker DJ, Merkus D (2019) Intervening with the nitric oxide pathway to alleviate pulmonary hypertension in pulmonary vein stenosis. J Clin Med. https://doi.org/10.3390/jcm80 81204

59. van Essen GJ, Te Lintel HM, Sorop O, Heinonen I, van der Velden J, Merkus D, Duncker DJ (2018) Cardiovascular function of modern pigs does not comply with allometric scaling laws. Sci Rep 8:792. https://doi.org/10.1038/s41598-017-18775-z

60. Vanderpool RR, Saul M, Nouraie M, Gladwin MT, Simon MA (2018) Association between hemodynamic markers of pulmonary hypertension and outcomes in heart failure with preserved ejection fraction. JAMA Cardiol 3:298-306. https://doi.org/10.1001/jamac ardio.2018.0128

61. Woolley RJ, Ceelen D, Ouwerkerk W, Tromp J, Figarska SM, Anker SD, Dickstein K, Filippatos G, Zannad F, Marco M, Ng L, Samani N, van Veldhuisen D, Lang C, Lam CS, Voors AA (2021) Machine learning based on biomarker profiles identifies distinct subgroups of heart failure with preserved ejection fraction. Eur J Heart Fail. https://doi.org/10.1002/ejhf.2144

62. Zhao Y, Vanhoutte PM, Leung SW (2015) Vascular nitric oxide: beyond eNOS. J Pharmacol Sci 129:83-94. https://doi.org/10. 1016/j.jphs.2015.09.002

63. Zhou Z, de Beer VJ, de Wijs-Meijler D, Bender SB, Hoekstra M, Laughlin MH, Duncker DJ, Merkus D (2014) Pulmonary vasoconstrictor influence of endothelin in exercising swine depends critically on phosphodiesterase 5 activity. Am J Physiol Lung Cell Mol Physiol 306:L442-452. https://doi.org/10.1152/ajplu ng.00057.2013 